FUENTEALBA, Pablo; ROJAS, Juan; LARRAÍN, Beatriz; BARRIGA, Omar, ¿Quiénes

son las personas que menos apoyan los principios penales y procesales penales en la

sociedad? Estudio piloto en el Gran Concepción, Chile.

Polít. crim. Vol. 14, No 27 (Julio 2019), Art. 14, pp. 491-519

[http://politcrim.com/wp-content/uploads/2019/06/Vol14N27A14.pdf]

\title{
¿Quiénes son las personas que menos apoyan los principios penales y procesales penales en la sociedad? Estudio piloto en el Gran Concepción, Chile.
}

\section{Who are the people that less support the principles of Criminal and Procedure Criminal Law in society? Study in the Greater Metropolitan Area of Concepción, Chile.}

Pablo J. Fuentealba Carrasco

Facultad de Ciencias Sociales, Departamento de Sociología, Universidad de Concepción, Chile. pablofuentealba1@gmail.com

Juan S. Rojas González

Facultad de Ciencias Sociales, Departamento de Sociología, Universidad de Concepción, Chile. juansebarojas@udec.cl

Beatriz E. Larraín Martínez

Facultad de Ciencias Jurídicas y Sociales, Departamento de Derecho Público, Universidad de Concepción, Chile.

blarrain@udec.cl

Omar A. Barriga

Facultad de Ciencias Sociales, Departamento de Sociología, Universidad de Concepción, Chile.

obarriga@udec.cl

\section{Resumen}

En el actual contexto del punitivismo, la ciudadanía hoy parece adherir poco a los principios penales y procesales-penales. Pero, ¿es esta adhesión homogénea en la población o varía de acuerdo a ciertos grupos o categorías? El objetivo del artículo ha sido comparar los niveles de adhesión a los principios penales de acuerdo al sexo, tramo etario, nivel educacional y adscripción política. Se utilizó la Escala de Adhesión a los Principios del Derecho Penal (EAPDP), compuesta por 46 ítems tipo Likert, aplicada a una muestra consecutiva de 369 casos en el Gran Concepción, Chile. Se efectuó una caracterización simple empleando técnicas bivariadas (t-Student y ANOVA) y pruebas post hoc. Los resultados mostraron que las mujeres, las personas con niveles educacionales más bajos y las personas con orientación política de derecha, presentan menores niveles de apoyo a los principios penales tanto en la Escala General como en algunas subescalas. No se encontraron diferencias de acuerdo al tramo etario. Así, la investigación profundiza en este nuevo tema vinculado al ámbito del punitivismo y la sociología jurídica. 
Palabras clave: Actitudes Punitivas, Punitivismo, Populismo Penal, Miedo al Delito, Política Criminal.

\begin{abstract}
In the current context of the punitivism, citizenry seems not to adhere to the principles of Criminal and Procedural Criminal Law. But, is the adherence homogeneous in the population or it variates according to the studied group? The aim of this paper has been to compare the levels of adherence to the principles of Criminal according to sex, age stretch, educational level and political adscription. The Scale of Adherence to the Principles of Criminal Law (SAPCL) was used, composed of 46 Likert-Type items, applied to a consecutive sample, made up by 369 cases in the Greater Metropolitan Area of Concepción, Chile. A simple characterization was effected, using bivariate techniques ( $\mathrm{t}$-Student and ANOVA) and post hoc tests. The results shown that women, people with lower educational levels and right-wing political adscription, exhibit lower levels of support toward the principles of Criminal Law, both in the General Scale and in some subscales. None differences according to the age were found. Thus, this research enables us to deepen on this new topic, linked with the subjects of punitivism and Sociology of Law.
\end{abstract}

Key words: Punitive Attitudes, Punitivism, Penal Populism, Fear of Crime, Criminal Policy.

\title{
Introducción
}

Los principios penales y procesales penales modernos influyeron en las legislaciones de las democracias liberales actuales. De este modo, principios tales como la presunción de inocencia, la legalidad, el derecho al debido proceso, la humanidad de las penas, entre otros, fueron positivizándose paulatinamente en la legislación (en los códigos, constituciones, tratados internacionales) ${ }^{1}$ conformándose el llamado Estado de Derecho ${ }^{2}$.

Sin embargo, el hecho de que la mayor parte de los principios se hayan institucionalizado, no implica que la opinión pública los apoye. Al contrario, en el contexto actual, los medios y redes sociales muestran que la opinión pública parecería cuestionarlos fuertemente. La impopularidad que implica el que no se apliquen medidas cautelares, la demanda por un aumento de las penas para delitos de menor lesividad que afectan el principio de proporcionalidad, serían algunos ejemplos de este cuestionamiento. Esto indicaría que, posiblemente, no existe un adecuado consenso en torno a los principios en los cuales se han inspirado muchas de las leyes penales y procesales penales actuales (de ahora en adelante sólo los llamaremos principios penales).

\footnotetext{
${ }^{1}$ ETCHEBERRY, Alfredo, Derecho Penal: Parte general, Santiago: Editorial Jurídica de Chile, 1998, passim. RUIZ, Enrique, El Derecho Penal Sustantivo y el Proceso Penal. Garantías constitucionales básicas en la realización de la justicia, Madrid: Colex, 1997, passim; SILVA, Jesús-María, Aproximaciones al Derecho Penal Contemporáneo, Barcelona: José María Bosch S.A., 1992, passim.

${ }^{2}$ BACIGALUPO, Enrique, Derecho Penal y el Estado de Derecho, Santiago: Editorial Jurídica de Chile, 2005, passim.
} 


\section{Polít. crim. Vol. 14, № 27 (Julio 2019), Art. 14, pp. 491-519 [http://politcrim.com/wp-content/uploads/2019/05/Vol14N27A14.pdf]}

Nuestra investigación no intenta responder a la pregunta sobre cuál es el nivel de adhesión a los principios penales y procesales penales, ya que esto, en cierta medida, ya ha sido abordado a nivel exploratorio (como veremos más adelante). Más bien nos hemos preguntado ¿Quiénes son las personas que más (o menos) apoyan estos principios? Ahora mostraremos qué es lo que se sabe en torno a este tema para poder otorgarle un marco teórico de referencia que permita enmarcar nuestra investigación.

En el contexto nacional e internacional, algunas mediciones han intentado conocer el nivel de apoyo hacia algunos principios penales, pero éstas no están exentas de problemas. Primero, muchas veces se consulta solamente por uno o dos principios aislados ${ }^{3}$. Esto no permite saber si la ciudadanía acepta el conjunto de principios penales, sino que sólo puede conocerse el nivel de apoyo ante algunos principios particulares. Segundo, la pregunta se formula descontextualizada o abstractamente, porque el reactivo no se asocia a delitos específicos. Por ejemplo, se pregunta ¿una persona debería ser considerada inocente mientras no se demuestre que es culpable? ${ }^{4}$, en vez de ¿un acusado de homicidio, pedofilia, asalto, debería ser considerado inocente mientras no se demuestre su culpabilidad? La formulación abstracta puede incidir en la respuesta, ya que un entrevistado bien puede afirmar que apoya un principio consultado a través de una pregunta abstracta, pero rechazarlo cuando debe considerar un evento real (p.ej. cuando se informa sobre asesinatos en medios de comunicación, sus cercanos son víctimas, etc.). Por ello, estos reactivos serían medidas cuestionables.

Desde otra perspectiva, la literatura sobre el punitivismo ha mostrado que los ideales penales modernos comenzarían a perder apoyo en la opinión pública y que, en cambio, se estaría abriendo paso hacia una mayor punitividad y/o cultura del control. De esta forma, ideas tales como el bienestarismo penal, la proporcionalidad de la pena, el ideal de rehabilitación o la idea del Estado mínimo estarían declinando. Desde las actitudes punitivas, las demandas por penas represivas o retributivas (bajo la creencia de que producirán disminución en el delito), el incremento de las medidas de seguridad y el derecho penal del enemigo, serían ideas en alza, tema especialmente estudiado por la literatura sobre punitivismo ${ }^{5}$. Sin embargo, estas conclusiones también han sido cuestionadas, ya que el nivel de punitivismo presentaría variaciones dependiendo de la metodología empleada. Así, cuando se emplean metodologías de "caso-escenario", donde el entrevistado debe aplicar castigos con diversas alternativas, o

\footnotetext{
${ }^{3}$ Por ejemplo, CENTRO UC ENCUESTAS Y ESTUDIOS LONGITUDINALES, Percepción del Servicio de la Defensoría Penal Pública. Santiago, Chile: Facultad de Ciencias Sociales, Pontificia Universidad Católica de Chile, 2016; MARKET OPINION RESEARCH INVESTIGATION, Barómetro de la Política Abril 2016, Santiago, Chile: CERC-MORI, 2016.

${ }^{4}$ CENTRO UC ENCUESTAS Y ESTUDIOS LONGITUDINALES, Percepción, cit. nota ${ }^{\circ} 3$.

${ }^{5}$ DIEZ RIPOLLÉS, José Luis, "El nuevo modelo penal de la seguridad ciudadana", Revista Electrónica de Ciencia Penal y Criminología, n 3 (2004), A6, pp. 1-34; DIEZ RIPOLLÉS, José Luis, "De la sociedad del riesgo a la seguridad ciudadana: un debate desenfocado", Revista Electrónica de Ciencia Penal y Criminología, $\mathrm{n}^{\circ} 1$ (2005), A7, pp. 1-37. GARLAND, David, La cultura del control, España: Ediciones Gedisa, 2005, passim; ROBERTS, Julian V.; STALANS, Loretta J.; INDERMAUR, David; HOUGH, Mike, Penal populism and public opinion: five lessons from five countries, New York: Oxford University Press, 2003 passim; ROBERTS, Julian V.; HOUGH, Mike, Understanding public attitudes to criminal justice, Maidenhead, UK: Open University Press, 2005.
} 
cuando se le proporciona información contextual y/o sobre el funcionamiento del sistema de justicia, el punitivismo tiende a disminuir ${ }^{6}$. Esto no supone desconocer el hecho de que el punitivismo es elevado en la actualidad, pero sí implica que deben introducirse ciertos matices. En este sentido, la población tendería a ser menos punitivista de lo que se piensa o manifiesta espontáneamente, y/o bien la actitud punitiva tendería a disminuir bajo contextos informados ${ }^{7}$.

No existe unanimidad respecto a la definición y operacionalización del miedo al delito ${ }^{8}$, sin embargo, se considera que influye en el desarrollo de las actitudes punitivas ${ }^{9}$. En algunas oportunidades el miedo al delito se ha entendido como una respuesta emocional negativa de nerviosismo o ansiedad frente a la posibilidad de ser víctima de delito, como la probabilidad o riesgo calculado de victimización, como las conductas autoprotectoras frente al delito o como estimaciones generales del estado de desorden y crimen en la sociedad, entre otras posibles conceptualizaciones ${ }^{10}$. Aunque con bastantes inconsistencias (en parte debido a los problemas de conceptualización y operacionalización mencionados), la mayoría de las investigaciones han encontrado que serían las mujeres ${ }^{11}$, los sujetos de mayor edad ${ }^{12}$ y las

${ }^{6}$ ROBERTS, Julian V.; HOUGH, Mike; JACKSON, Jonathan; GERBER, Monica M., "Public Opinion towards the Lay Magistracy and the Sentencing Council Guideline: the effects of information on attitudes", British Journal of Criminology, vol. 52, $\mathrm{n}^{\circ} 6$ (2012), pp. 1072-1091; ROBERTS/HOUGH, Understanding, cit. nota $\mathrm{n}^{\circ} 5$. VARONA, Daniel, "Ciudadanos y actitudes punitivas: un estudio piloto de población universitaria española", Revista Española de Investigación Criminológica, $\mathrm{n}^{\circ} 6$ (2008), A8, pp. 1-38; VARONA, Daniel, ¿"Somos los españoles punitivos?: actitudes punitivas y reforma penal en España", Indret: Revista para el Análisis del Derecho, $\mathrm{n}^{\circ} 1$ (2009), pp. 1-31.

${ }^{7}$ AIZPURÚA, Eva; FERNÁNDEZ-MOLINA, Ester, “Información, ¿antídoto frente al populismo punitivo? Estudio sobre las actitudes hacia el castigo de los menores infractores y el sistema Judicial Juvenil, Revista Española de Investigación Criminológica, $\mathrm{n}^{\circ} 9$ (2011), A3, pp. 1-29. MATTHEWS, Roger, "The Myth of Punitiveness", Theoretical Criminology, vol. 9, $\mathrm{n}^{\circ} 2$ (2005), pp. 175-201; ROBERTS/STALANS/INDERMAUR/HOUGH, Mike, Penal populism, cit. nota ${ }^{\circ} 5$; TYLER, Tom; BOECKMANN, Robert, "Three strikes and you are out, but why? The psychology of public support for punishing rule-breakers", Law and Society Review, vol. 31, n 2 (1997), pp. 237-266;

${ }^{8}$ HENSON, Billy; REYNS, Bradford W., "The Only Thing We Have to Fear Is Fear Itself...and Crime: The Current State of the Fear of Crime Literature and Where It Should Go Next", Sociology Compass, vol. 9, $\mathrm{n}^{\circ} 2$ (2015), pp. 91-103.

${ }^{9}$ ARMBORST, Andreas, "How fear of crime affects punittive attitudes", European Journal of Criminal policy and research, vol. 23, n⿳3 (2017), pp. 461-481.

${ }^{10}$ FERRARO, Kenneth F.; LAGRANGE, Randy, "The Measurement of Fear of Crime", Sociological Inquiry, vol. 57, n' 1 (1987), pp. 70-97; GAROFALO, James, "The Fear of Crime: Causes and Consequences", Journal of Criminal Law and Criminology, vol. 72, $\mathrm{n}^{\circ} 2$ (1981), pp. 839-857; HENSON/REYNS "The Only Thing", cit. nota $\mathrm{n}^{\circ}$ 8; RADER, Nicole E., "The Threat of Victimization: A Theoretical Reconceptualization of Fear of Crime", Sociological Spectrum: Mid-South Sociological Association, vol. 24, $\mathrm{n}^{\circ} 6$ (2004), pp. 689-704; RADER, Nicole E., "Fear of Crime", Oxford Research Encyclopedia of Criminology (2017).

${ }^{11}$ FERRARO, Kenneth F., "Women's fear of victimization: Shadow of sexual assault?", Social Forces, vol. 75, n 2 (1996), pp. 667-690; HENSON/REYNS "The Only Thing", cit. nota ${ }^{\circ}$ 8.; LAGRANGE, Randy; FERRARO, Kenneth F., "Assessing Age and Gender Differences in Perceived Risk and Fear of Crime", Criminology, vol. 27, n 4 (1989), pp. 697-720; RADER, Nicole E.; HAYNES, Stacy H., "Gendered fear of crime socialization: An extension of Akers's social learning theory", Feminist Criminology, vol. 6, n 4 (2011), pp. 291-307.

${ }^{12}$ BEAULIEU, Marie; DUBÉ, Micheline; BERGERON, Christian; COUSINEAU, Marie-Marthe, "Are elderly men worried about crime?, Journal of Aging Studies, vol. 21, n 4 (2007), pp. 336-346. HALE, Chris, "Fear of crime: A review of the literature", International Review of Victimology, vol. 4, n 2 (1996), pp. 79-150; 


\section{Polít. crim. Vol. 14, No 27 (Julio 2019), Art. 14, pp. 491-519 [http://politcrim.com/wp-content/uploads/2019/05/Vol14N27A14.pdf]}

personas con menores niveles educacionales ${ }^{13}$, quienes poseen mayores niveles de miedo al delito, dado que son grupos que se encuentran y/o se perciben a sí mismos cómo más amenazados. Las personas con ideología política de derecha también serían más propensas a sentir temor ${ }^{14}$, lo que se explicaría -en parte- porque visualizan al delito como más grave y, también, por poseer una mayor adhesión a las normas convencionales ${ }^{15}$. También se ha mostrado que los medios de comunicación (y la exposición a ellos) pueden jugar un rol importante al contribuir al incremento de los niveles de miedo al delito. De esta forma pueden generar una visión distorsionada de la realidad delictual (p.ej. sensación social de impunidad o indulgencia frente a la delincuencia, la creencia de que el delito ha aumentado) y contribuir al incremento de los niveles de inseguridad ciudadana percibidos, aunque este impacto puede ser heterogéneo y variar dependiendo de los contextos y categorías sociales, tales como el sexo y la edad ${ }^{16}$, así como de las audiencias ${ }^{17}$. Así, con independencia de que los niveles objetivos de victimización se mantengan, aumenten o disminuyan, la sensación de miedo al delito tiende a ser elevada en la mayor parte de las sociedades actuales ${ }^{18}$, lo cual puede tener como consecuencia niveles más altos de actitud punitiva, dado que existe la creencia de que el castigo es un buen instrumento para reducir el crimen ${ }^{19}$.

Hemos discurrido sobre las relaciones entre miedo al delito, medios de comunicación y su influencia en el punitivismo para tener un fundamento que permita otorgarle sentido teórico

ZIEGLER, Raphael; MITCHELL, David B., “Aging and fear of crime: An experimental approach to an apparent paradox", Experimental Aging Research, vol. 29, n 2 (2003), pp. 173-187.

${ }^{13}$ HALE, "Fear of crime", cit. nota n'10; RADER, "Fear of Crime", cit. nota $\mathrm{n}^{\circ} 10$.

${ }^{14}$ AMAYA, Laura; ESPINOSA, Agustín; VOZMEDIANO, Laura, "Relaciones entre el Miedo al delito y el Autoritarismo de Derecha en estudiantes universitarios de Lima-Perú”, Boletín de Psicología, 103 (2011), pp. 7-28; DUCKITT, John; SIBLEY, Chris G., "Right wing authoritarianism, social dominance orientation and the dimensions of generalized prejudice”, European Journal of Personality, vol. 21, n 2 (2007), pp. 113-130; MEDINA, Juanjo, “Inseguridad Ciudadana, Miedo al Delito y Policía en España”, Revista Electrónica de Ciencia Penal y Criminología, n 3 (2003), A5, pp. 1-21.

${ }^{15}$ GERBER, Mónica; JACKSON, Jonathan, "Justifying violence: legitimacy, ideology and public support for police use of force", Psychology, Crime and Law, vol. 23, n 1 (2017), pp.79-95

${ }^{16}$ CALLANAN/ROSENBERGER “Media, Gender”, cit. nota n 18 . INTRAVIA, Jonathan; WOLFF, Kevin T.; PAEZ, Rocio; GIBBS, Benjamin R., "Investigating the relationship between social media consumption and fear of crime: A partial analysis of mostly young adults", Computers in Human Behavior, vol. 77 (2017), pp. 158-168. KOHM, Steven A.; WAID-LINDBERG, Courtney A.; WEINRATH, Michael; O'CONNORSHELLEY, Tara; DOBBS, Rhonda R., "The Impact of Media on Fear of Crime among University Students: A Cross-National Comparison", Canadian Journal of Criminology and Criminal Justice, vol. 54, n 1 (2012), pp. 67-100.

${ }^{17}$ JAMIESON, Patrick E.; ROMER, Daniel, "Violence in Popular U.S. Prime Time TV Dramas and the Cultivation of Fear: A Time Series Analysis", Media and Communication, vol. 2, n 2 (2014), pp. 31-41.

${ }^{18}$; BROWNE, Magdalena; TOMICIC, Vinsja, "Crimen y temor, el rol de los medios", Cuadernos.Info, $\mathrm{n}^{\circ} 20$ (2011), pp. 21-36; CALLANAN, Valerie; ROSENBERGER, Jared S., "Media, Gender, and Fear of Crime", Criminal Justice Review, vol. 40, n 3 (2015), pp. 322-339; FUENTES, Juan, "Los medios de comunicación y el Derecho Penal", Revista Electrónica de Ciencia Penal y Criminología, n 16 (2005), A7, pp. 1-51; KOHM/WAID-LINDBERG/WEINRATH/O'CONNOR-SHELLEY/DOBBS, "The Impact of Media", cit. nota n¹6; MEDINA, Juanjo, "Inseguridad Ciudadana...", cit. nota $n^{\circ}$ 14; MORGAN, Michael; SHANAHAN, James; SIGNORIELLI, Nancy, "Cultivation Theory in the Twenty-First Century", en: FORTNER, Robert S.; FACKLER, P. Mark (Eds.), The Handbook of Media and Mass Communication Theory, Hoboken, NJ: John Wiley and Sons, Inc., 2014, pp. 480-497; SOTO, Susana, "La influencia de los medios en la percepción social de la delincuencia”, Revista Electrónica de Ciencia Penal y Criminología n 9 (2005), A7, pp 1-46.

19 GARLAND, La cultura, cit. nota $\mathrm{n}^{\circ}$ 5; VARONA, Daniel, "Medios de comunicación y punitivismo", Indret: Revista para el Análisis del Derecho, n 1 (2011), pp. 1-34. 
a nuestros datos. Sin embargo, debemos advertir que las variables de miedo al delito y exposición (o hábitos o confianza) a mass media, no serán testeadas en este trabajo, ya que nuestro objetivo ha consistido en llevar a cabo una caracterización sociodemográfica de la adhesión a los principios penales. De esta manera, estos elementos teóricos los usaremos como un apoyo para hacer una interpretación plausible de nuestros resultados. Si bien no es muy habitual incorporar temas que finalmente no serán testeados, creemos tener fundamento para hacerlo en esta oportunidad, ya que Fuentealba y Barriga han encontrado una correlación negativa entre la percepción de inseguridad el apoyo ciudadano a los principios penales. Por ello, sería esperable que los grupos (p.ej. por sexo, edad) que perciban mayor inseguridad, sean los que adhieran menos a los principios del derecho penal ${ }^{20}$. Esto nos permite justificar la incorporación del tópico del miedo al delito para conectarlo con tema de la adhesión en nuestro trabajo.

Ideológicamente, las posiciones más conservadoras estarían relacionadas con la promoción de políticas punitivas ${ }^{21}$. Esto puede abordarse desde dos visiones de mundo ampliamente estudiadas por la psicología política que son el autoritarismo de derecha (RWA: Right-Wing Authoritarianism) y la orientación hacia la dominación social (SDO: Social Dominance Orientation). Las escalas SDO y RWA son coherentes en términos de correlación con las preguntas de autoubicación política de un único ítem en ejes izquierda-derecha ${ }^{22}$. Quienes poseen altos niveles en RWA valoran más el respeto por la obediencia, autoridades y jerarquías, apoyo a las tradiciones, normas y valores tradicionales, creen en el control social coercitivo, siendo fuertemente convencionalistas. Quienes presentan altos grados de SDO creen en relaciones sociales no igualitarias en lo económico, en el derecho de los grupos poderosos para dominar sobre los menos poderosos, bajo una visión netamente darwiniana de la sociedad, en un mundo amenazante y competitivo. Para ambas visiones, aunque por diferentes motivos, el castigo constituiría un respaldo simbólico al statu quo (normas tradicionales o jerarquías), aplicado negativamente a quienes puedan suponer desorden o amenazas al orden social. Por ello, serían partidarios de políticas orientadas al control de las amenazas, que promuevan el orden y la seguridad, apoyando incluso la restricción de libertades civiles ${ }^{23}$, muchas veces bajo una lógica de disuasión y retribución ${ }^{24}$.

\footnotetext{
${ }^{20}$ FUENTEALBA, Pablo; BARRIGA, Omar, "Primera aproximación a la construcción de una Escala de Adhesión a los principios del Derecho Penal (EAPDP). Estudio Piloto en el Conurbano del Gran Concepción, Chile", Revista Internacional de Sociología, vol. 75, nº 2 (2017), pp. 60.

${ }^{21}$ GERBER/JACKSON, "Justifying violence", cit. nota $n^{\circ} 15$; TYLER/BOECKMANN, "Three strikes", cit. nota $\mathrm{n}^{\circ} 7$.

${ }^{22}$ DUCKITT, John; BISUMIC, Boris; KRAUSS, Stephen, "A tripartite approach to Right-Wing Autoritarianism", Political Psychology, vol. 31, no 5 (2010), pp. 685-715; GRINA, Jana; BERG, Robin; AKRAMI, Nazar; SIDANIUS, Jim, "Political Orientation and Dominance: Are people on the political right more dominant?”, Personality and Individual Differences, vol. 1, no 94 (2016), pp. 113-117; PRATTO, Felicia; SIDANIUS, James; STALLWORTH, Lisa; MALLE, Bertram, "Social Dominance Orientation: A personality variable predicting social and political attitudes", Personality and Social Psychology, vol. 67, n 4 (1994), pp. 741-763.

${ }^{23}$ DUCKITT, John, "Punishment attitudes: their social and psychological basis", en OSWALD, Margit E.; BIENECK; Steffen; HUPFELD-HEINEMANN, Jorg, Social Psychology of Punishment of Crime. Oxford, UK: Wiley-Blackwell, 2009, pp. 75-92; GERBER/JACKSON, “Justifying violence”, cit. nota $n^{\circ} 15$; PRATTO/SIDANIUS/STALWORTH/MALLE, "Social Dominance Orientation: a personality", cit. nota n” 22. ${ }^{24}$ COLÉMONT, Ariane; VAN HIEL, Alain; CORNELIS, Ilse, "Five-Factor Model personality dimensions and
} 


\section{Polít. crim. Vol. 14, No 27 (Julio 2019), Art. 14, pp. 491-519 [http://politcrim.com/wp-content/uploads/2019/05/Vol14N27A14.pdf]}

Concordantemente, bajo la concepción individualista propia del neoliberalismo, el delito sería comprendido como una responsabilidad individual, no vinculada a desigualdades sociales, lo cual constituye una visión opuesta al bienestarismo que reconoce una responsabilidad colectiva fundada en la existencia de oportunidades desiguales en la sociedad $^{25}$. Todo esto, permite comprender por qué los sectores más próximos a la derecha, apoyan en mayor medida la pena de muerte, castigos más severos, con menores niveles de empatía hacia delincuentes, no creen en la rehabilitación, perciben el delito de forma mucho más grave o piensan que el castigo es una forma apropiada de disuasión y de reforma, elementos que pueden considerarse como indicadores del punitivismo.

En el caso de Chile, la distinción derecha-izquierda, supone una suerte de mixtura de los ejes liberal-conservador, capitalismo-socialismo (y/o bienestarismo) y autoritarismo-democracia. Así, las posiciones de derecha, supondrían un conservadurismo en lo valórico, neoliberalismo en lo económico y un respaldo a la dictadura de Pinochet en lo político. Las posiciones de izquierda, supondrían liberalismo en lo valórico, bienestarismo y/o socialismo en la economía y partidarios del retorno a la democracia ${ }^{26}$. Evidentemente, entre estos ejes existen posiciones intermedias, grados, complejidades y aristas que se pierden en esta presentación simplificada, pero esta exposición rescata los elementos esenciales de los clivajes o fisuras generativas del eje derecha-izquierda.

El enfoque de las actitudes punitivas no constituye un marco que a primera vista pueda equipararse con la adhesión a los principios penales. Si consideramos las medidas tradicionales de punitivismo, tales como apoyo a la pena de muerte, aumento de las penas, entre otras, hay bastantes equivalencias con la adhesión (p.ej. actitud punitiva con gradualidad o humanidad de las penas). Sin embargo, en otros ámbitos, la equiparación con las medidas tradicionales sería cuestionable (p.ej. actitud punitiva con legalidad y debido proceso). Esto llevaría a pensar que punitivismo y adhesión a los principios penales, tal vez, debiesen tratarse como variables distintas. Incluso Tyler y Boeckmann ${ }^{27}$ han abordado diferenciadamente la actitud punitiva y las protecciones procesales para luego correlacionar ambas variables. Sin embargo, Feeley considera en su medición objetiva del proceso penal, que la ausencia de garantías y derechos, tales como non bis in ídem, derecho a guardar silencio, entre otros, pueden llevar a un aumento del punitivismo ${ }^{28}$. Este aspecto es retomado por Hamilton quien introduce el elemento procesal en su medición multidimensional del punitivismo estatal, junto con otros indicadores, tales como las tasas de prisión, las

right-wing attitudes: Psychological bases of punitive attitudes?", Personality and Individual Differences, vol. 50, $\mathrm{n}^{\circ} 4$ (2011), pp. 486-491; SIDANIUS, Jim; MITCHELL, Michael; HALLEY, Hilary; NAVARRETE, Carlos, "Support for harsh criminal sanctions and criminal justice beliefs: a social dominance perspective", Social Justice Research, vol. 19, nº 4 (2006), pp. 433-450.

${ }^{25}$ GARLAND, La cultura, cit. nota ${ }^{\circ} 5$.

${ }^{26}$ ALTMAN, David; LUNA, Juan Pablo; PIÑEIRO, Rafael; TORO, Sergio, "Partidos y sistemas de partidos en América Latina: Aproximaciones desde la encuesta a expertos 2009", Revista de Ciencia Política, $\mathrm{N}^{\circ}$. Vol. (2009) pp. 775-798; TIRONI, Eugenio; AGÜERO, Felipe, “Sobrevivirá el nuevo paisaje político chileno?” Revista Estudios Públicos, vol. 74, nº 1 (1999), pp. 151-158.

${ }^{27}$ TYLER/BOECKMANN, "Three strikes", cit. nota ${ }^{\circ} 7$.

${ }^{28}$ FEELEY, Malcom, The process is the punishment: handling cases in a lower criminal court, Russell Sage Foundation, 1992. 
condiciones carcelarias, entre otros ${ }^{29}$. Sin embargo, tanto Feeley como Hamilton incorporan el aspecto procesal como medida de punitivismo estatal en términos objetivos, pero no como medida de actitudes punitivas, que son el aspecto subjetivo del punitivismo.

Finalmente, la adhesión a los principios penales ha sido estudiada de forma más robusta en el contexto chileno. Conceptualmente, la adhesión ha sido entendida como "el nivel en el que los principios penales y procesales penales han sido incorporados subjetivamente (nivel cognitivo, afectivo y conductual) por los individuos, siendo aceptados, comprendidos y considerados válidos y legítimos por éstos, convirtiéndose en reglas generales de razonamiento para interpretar y juzgar situaciones jurídicas, y orientar acciones en base a estos mismos principios" ${ }^{30}$. De esta forma, el estudio de la adhesión a los principios penales constituye un avance en la comprensión, no del puntivismo estatal -objetivo- como lo hacen Feeley y Hamilton, sino de las actitudes punitivas. De esta forma, el mayor o menor apoyo a los principios penales y procesales penales, resulta relevante porque tendría implicancias punitivas, dado que se relacionaría con la medida en la que la ciudadanía adhiere o no a las limitaciones y controles internos del poder de castigo que posee el estado y, por lo tanto, a sus inherentes consecuencias sobre el deseo de castigo y, por consiguiente, sobre el castigo en $\mathrm{si}^{31}$. Este tema apenas ha sido abordado por la literatura y en esto radica el que el estudio de esta variable tenga un valor no sólo contextual, sino disciplinar. Operacionalmente, la adhesión fue medida a través de la Escala de Adhesión a los Principios Penales (EAPDP), que está compuesta por 46 reactivos tipo Likert. Mediante Análisis Factorial Exploratorio (AFE) y coeficiente alfa de Cronbach, los autores establecieron que (Tabla 1):

- A nivel exploratorio la escala era válida (que mide el constructo que afirma medir) y confiable (que la medición es precisa).

- El fenómeno de la adhesión es multidimensional, ya que los 46 ítems se agruparon en seis factores a partir de los cuales se construyeron seis subescalas y una escala general.

- Los resultados descriptivos encontrados mostraron que, en general, la ciudadanía no apoya los principios penales.

- Existía una correlación inversa entre el miedo al delito y la adhesión.

\footnotetext{
${ }^{29}$ HAMILTON, Claire, "Reconceptualizing penalty: Towards a multidimensional measure of punitiveness", British Journal of Criminology, vol. 54, nº 2 (2014), pp. 321-343.

${ }^{30}$ FUENTEALBA/BARRIGA, "Primera aproximación...", cit. nº20. FUENTEALBA, Pablo; LARRAÍN, Beatriz; BARRIGA, Omar, "¿Adhiere la ciudadanía a los principios del derecho penal y procesal penal? El caso del Gran Concepción, Chile", Política Criminal, vol. 13, nº 25 (2018), pp. 233-263.

${ }^{31}$ Esto, por la influencia que la opinión pública puede tener sobre las políticas públicas y el Estado, tornándolos más punitivos. P.ej., ver TONRY, Michael. "Symbol, substance and severity in western penal policies", Punishment \& Society, vol. 3 n 4 , pp. (2001) 517-536.
} 
Polít. crim. Vol. 14, No 27 (Julio 2019), Art. 14, pp. 491-519

[http://politcrim.com/wp-content/uploads/2019/05/Vol14N27A14.pdf]

\section{Tabla 1}

Descriptivos generales para

Nivel de adhesión a los principios penales y procesales-penales

\begin{tabular}{lccc}
\hline Subescalas & $\begin{array}{c}\text { \% que } \\
\text { adhiere }\end{array}$ & $M$ & DE \\
\hline Adhesión al Principio de Gradualidad de la Pena & $31,5 \%$ & 2,59 & 0,930 \\
Adhesión al Derecho al Debido Proceso & $55,4 \%$ & 3,40 & 0,679 \\
$\begin{array}{l}\text { Adhesión al Principio de Intervención Mínima y Legalidad } \\
\text { en la Aplicación de Penas y Medidas }\end{array}$ & $18,6 \%$ & 2,26 & 0,692 \\
$\begin{array}{l}\text { Adhesión al Principio de Humanidad de las Penas desde un } \\
\text { Sistema Estatal de Justicia }\end{array}$ & $52,6 \%$ & 3,34 & 0,878 \\
$\begin{array}{l}\text { Adhesión al Principio de Legalidad Penal } \\
\text { Adhesión a los Derechos Sociales y de Trato a los }\end{array}$ & $31,2 \%$ & 2,68 & 0,936 \\
Condenados y Acusados & $47,8 \%$ & 3,24 & 0,799 \\
Totales Escala General (EAPDP) & $40,4 \%$ & 2,92 & 0,552 \\
\hline
\end{tabular}

${ }^{a}$ Niveles Muy bajo (1), Bajo (2) e Intermedio (3) de apoyo, fueron considerados como No adhiere.

${ }^{\mathrm{b} N i v e l e s ~ A l t o ~(4) ~ y ~ M u y ~ a l t o ~(5) ~ d e ~ a p o y o ~ f u e r o n ~ c o n s i d e r a d o s ~ c o m o ~ A d h i e r e . ~}$

'Elaboración propia a partir de los datos obtenidos por Fuentealba \& Barriga.

Hoy resulta fundamental plantearse nuevas interrogantes a un nivel, al menos, correlacional. La pregunta que surge es: ¿Son estos niveles de disenso/consenso en torno a los principios homogéneos en la población o, más bien, existen grupos que presentan mayores (o menores) niveles de adhesión a estos principios? De esta forma, el objetivo del artículo ha consistido en comparar los niveles de adhesión de acuerdo al perfil sociodemográfico (sexo, edad, nivel educacional) y político de los entrevistados mediante una caracterización simple.

Aunque nuestro tema aún está en una etapa relativamente exploratoria, creemos que es posible proponer algunas hipótesis orientadoras. Esperaríamos que la adhesión sea más baja en mujeres $\left(H_{1}\right)$, personas de más edad $\left(H_{2}\right)$, personas con menores niveles educacionales $\left(H_{3}\right)$ y personas con adscripción política de derecha $\left(H_{4}\right)$. Sin perjuicio de lo anterior, la mayor parte de argumentación que se presenta en la discusión proviene de la literatura criminológica sobre el fenómeno del miedo al delito, que establece relaciones con el perfil sociodemográfico y político.

Así, la investigación permitirá establecer las primeras relaciones entre la adhesión a los principios penales con variables de carácter sociodemográfico y político, contribuyendo al mejor conocimiento del fenómeno. Si bien mediante estos datos no es posible establecer causalidad, sino correlación (lo cual constituye una de las principales limitaciones del estudio), la caracterización efectuada permite identificar aquellos grupos que presentan mayores o menores niveles de apoyo en torno a este conjunto de principios de acuerdo al sexo, edad, nivel educacional y tendencia política. Desde el punto de vista práctico, la adecuada identificación de estos grupos permitiría orientar políticas públicas focalizadas. 


\section{Metodología}

\subsection{Diseño.}

Se utilizó un enfoque cuantitativo, mediante técnica de encuestas con cuestionario como instrumento de recolección de información, con datos primarios, utilizando la base de datos generada por Fuentealba y Barriga ${ }^{32}$.

\subsection{Muestra.}

La muestra es de tipo consecutiva (no probabilística) y estuvo compuesta por 369 entrevistados pertenecientes al Conurbano del Gran Concepción, Región del Bío Bio, Chile. Para el año 2015 presentaba una proyección poblacional de 1.040.348 habitantes (INE, $2015)^{33}$, siendo la segunda zona con mayor población del país después del Gran Santiago ${ }^{34}$. La recolección se efectuó mediante la selección de punto fijo en diversos sectores del Gran Concepción, desde los cuales se aplicó el cuestionario en hogares ubicados en manzanas cercanas al punto seleccionado. Se entrevistó a una persona por hogar, que fuera mayor de 18 años.

Se obtuvo representación de todas las comunas de la zona. La mayoría pertenece a la comuna de Concepción (40,3\%). De los entrevistados, un 55\% corresponde a mujeres y sus edades fluctúan entre los 18 y 81 años, con una media de 35,8 años. Se encuentran representados sujetos de diferentes perfiles políticos, y la mayoría se define como apolítico/sin ubicación $(39,8 \%)$. Un $26 \%$ posee educación primaria o secundaria (incompleta o completa), un $23 \%$ posee educación terciaria de tipo técnico-profesional no universitaria (incompleta o completa) y un $46,9 \%$ posee estudios universitarios completos/incompletos.

En la muestra existen grupos que se encuentran sobrerrepresentados respecto a la población o universo (tales como personas con estudios terciarios y jóvenes entre 18 y 29 años). Por no ser una muestra probabilística, no es posible generalizar los resultados, lo cual constituye una de las principales limitaciones del estudio. Sin embargo, la muestra es bastante heterogénea en su composición sociodemográfica y apropiada en tamaño para efectuar los test de hipótesis requeridos y establecer relaciones entre variables.

\footnotetext{
${ }^{32}$ FUENTEALBA/BARRIGA, "Primera aproximación", cit. nota $\mathrm{n}^{\circ}$ 20; FUENTEALBA /LARRAÍN/ BARRIGA, “¿Adhiere la ciudadanía?”, cit. nota n 30.

${ }^{33}$ La cifra corresponde a la suma de las proyecciones de población de las comunas del conurbano (Concepción, Coronel, Chiguayante, Hualpén, Hualqui, Lota, Penco, San Pedro de la Paz, Talcahuano y Tomé). Si bien la muestra no es probabilística, el tamaño de la muestra fue calculado considerando un $95 \%$ de nivel de confianza, un 5\% de margen de error y una varianza heterogénea de 50\%. INSTITUTO NACIONAL DE ESTADÍSTICAS, “Actualización de Población 2002-2012 y Proyecciones 2015-2020, Provincia de Concepción", Santiago de Chile: INE, 2015.

${ }^{34}$ Hemos proporcionado la información correspondiente al Censo del año 2002 debido a que el Censo 2012 presentó problemas en la recolección de datos que implicaron su invalidación. Por esta razón, se optó por informar los datos correspondientes al Censo 2002 junto con su proyección de crecimiento.
} 


\section{Instrumento y medición}

\subsection{Perfil sociodemográfico y político.}

El perfil sociodemográfico fue medido del siguiente modo:

\section{Tabla 2}

Variables sociodemográficas y de adscripción política.

\begin{tabular}{|c|c|}
\hline Sexo & $\begin{array}{l}\text { Hombre }=0 \\
\text { Mujer }=1\end{array}$ \\
\hline $\begin{array}{l}\text { Tramo etario: pregunta } \\
\text { abierta recodificada } \\
\text { (nominal) }\end{array}$ & $\begin{array}{l}\mathrm{A}=18-29 \text { años } \\
\mathrm{B}=30-45 \text { años } \\
\mathrm{C}=46-59 \text { años } \\
\mathrm{D}=60 \text { o más }\end{array}$ \\
\hline $\begin{array}{l}\text { Nivel educacional }^{35} \text { : } \\
\text { Pregunta con } 12 \\
\text { categorías iniciales y } \\
\text { recodificada } \\
\text { (ordinal) }\end{array}$ & $\begin{array}{l}\mathrm{A}=\text { desde sin estudios hasta enseñanza media completa. } \\
\mathrm{B}=\text { desde sujetos con Educación Técnica incompleta/completa (carrera de 1-2 } \\
\text { años) hasta Educación Superior Profesional incompleta (carrera de } 4 \text { años en } \\
\text { Instituto Profesional). } \\
\mathrm{C}=\text { desde Educación Superior Profesional completa (Instituto profesional) hasta } \\
\text { Universitaria incompleta } \\
\mathrm{D}=\text { Universitaria completa o más. }\end{array}$ \\
\hline $\begin{array}{l}\text { Adscripción política } \\
\text { (¿Con cuál de las } \\
\text { siguientes tendencias } \\
\text { políticas se identifica } \\
\text { más?) (nominal) }\end{array}$ & $\begin{array}{l}\mathrm{A}=\text { Izquierda } \\
\mathrm{B}=\text { Centro izquierda } \\
\mathrm{C}=\text { Centro, o sin orientación clara. } \\
\mathrm{D}=\text { Centro Derecha } \\
\mathrm{E}=\text { Derecha }\end{array}$ \\
\hline
\end{tabular}

\subsection{Adhesión a los principios del derecho penal y procesal penal.}

Para medir la variable Adhesión a los principios del Derecho Penal y Procesal Penal, se utilizó la Escala de Adhesión a los Principios del Derecho Penal (EAPDP) desarrollada por Fuentealba y Barriga $^{36}$, cuyas características resumimos a continuación:

La escala se encuentra compuesta por 46 reactivos tipo Likert que miden el consenso en torno a 21 de estos principios penales directamente (y 3 indirectamente). La escala no mide en abstracto la adhesión a los principios, sino que éstos se vinculan a delitos de alta connotación social clasificados en dos niveles polares: delitos de alto rechazo social (p.ej. homicidio, pedofilia y violación) y de bajo rechazo social (p.ej. hurtos, cuento del tío, carterazos, lanzazos, entre otros ${ }^{37}$ ). Los delitos son presentados al entrevistado como

\footnotetext{
${ }^{35}$ La elaboración de estas categorías educacionales resulta especialmente compleja, puesto que no siempre hay plena coherencia teórica en la ordinalidad de la medición. Por ejemplo, ¿qué posee más rango en términos de cualificación: estudiar 2 años en la Universidad pero no terminar la carrera o bien estudiar una carrera técnica de 2 años y medio y terminarla? Para elaborar las categorías se consideró el criterio usado por la Consultora ADIMARK (Chile), generando categorías que resultasen interpretables teóricamente.

${ }^{36}$ FUENTEALBA/BARRIGA, "Primera aproximación", cit. nota n²0.

${ }^{37}$ Cuento del tío: Tipo de estafa menor. Usa el engaño y astucia para aprovecharse de la inocencia de la víctima (por ejemplo, cambiar dinero por un boleto de lotería supuestamente premiado). Carterazo o lanzazo: Robo por sorpresa. Forma de apropiación de especies sin uso de violencia, aparentando riñas o maniobras que generen confusión en lugares concurridos.
} 
ejemplos de cada nivel, más que como referencia a delitos específicos, ya que la finalidad de la escala consiste en evaluar la adhesión ante dos contextos polares de delito. De esta forma, el entrevistado debe indicar su nivel de acuerdo o desacuerdo ante las afirmaciones planteadas, las que integran el principio penal o procesal-penal con algunos de los niveles de delito, donde cada principio medido dispone de un par lógico de reactivos. Para no perder la equivalencia entre los ítems, se utilizan los mismos ejemplos para todas las preguntas/afirmaciones. Considerando que la población general estudiada carece de conocimientos jurídicos especializados y que, por lo tanto, puede desconocer los principios penales, así como muchos de los conceptos y términos legales usados normalmente ("irretroactividad", "taxatividad", "hurto", "imputado", "ministerio público"), los reactivos se formulan en lenguaje coloquial y corriente, sin hacer uso del lenguaje técnico. De esta manera, fueron formulados como expresiones accesibles a entrevistados de diversos niveles educacionales, pero donde cada ítem contenía el concepto del principio que se buscaba medir. Como ejemplo, los reactivos se formularon del siguiente modo (para el principio de plena prueba y duda razonable):

3.-Cuando finaliza un juicio por homicidio, violación o pedofilia, los jueces deberían castigar a un acusado cuando hay más probabilidades de que sea culpable, aunque puedan existir ciertas dudas fundadas de que tal vez no cometió el delito.

31.-Cuando finaliza un juicio por robo sin violencia, mecheo, lanzazo o cuento del tío, los jueces deberían castigar a un acusado cuando hay más probabilidades de que sea culpable, aunque puedan existir ciertas dudas fundadas de que tal vez no cometió el delito.

Posteriormente, los ítems se distribuyen aleatoriamente en el cuestionario. Ante cada afirmación, el entrevistado tiene 5 alternativas de respuesta (muy de acuerdo; de acuerdo; ni de acuerdo, ni en desacuerdo; en desacuerdo; muy en desacuerdo), con puntuaciones de 1-5 (preguntas en sentido contrario fueron recodificadas), de tal forma que valores cercanos a 1 indican baja aceptación del principio y valores cercanos a 5 indican alta adhesión a éste.

La medición no considera la adhesión ante delitos de rechazo social intermedio (p.ej. robo con violencia y asaltos, delito de lesiones) con el objetivo de reducir la extensión del cuestionario (implicaba aumentar de 46 a 69 preguntas) y, además, evitar la ambigüedad que pudiese producirse entre el nivel intermedio y los polos extremos de delitos. Además, la escala no contempla delitos cuya respuesta pudiese encontrarse condicionada por variables políticas o valóricas (p.ej. delitos de consumo y tráfico de drogas, terrorismo, estafas de grandes empresas), puesto que éstas no han sido objeto de control estadístico. Por ello, la escala incorpora aquellos delitos que presentan un rechazo social transversal por parte de la opinión pública.

Los principios medidos directamente son el (1) principio de culpabilidad, (2) principio de responsabilidad penal especial -distinción de responsabilidad entre adultos y adolescentes-, (3) trayectoria criminal (irreprochable conducta anterior), (4) reparación del daño causado, (5) principio de plena prueba (y duda razonable), (6) derecho de defensa material, (7) derecho a defensa técnica, (8) derecho a juez imparcial e (9) independiente, (10) legalidad de la prueba, (11) personalidad de la pena (o intrascendencia de la pena), (12) presunción de inocencia, (13) principio de peligrosidad, (14) subsidiariedad sancionatoria, (15) humanidad de las penas, (16) control de la ejecución penal, (17) sistema estatal de justicia, (18) 
legalidad penal como máxima taxatividad penal e (19) interpretativa, (20) derechos sociales $\mathrm{y}$ dignidad de los acusados y (21) rigor probatorio. Otros principios no medidos directamente, pero implícitos en los reactivos, fueron (22) reserva legal en lo penal, (23) irretroactividad penal e (24) in dubio pro reo. Debe consignarse que, si bien para cada principio se contaba con ítems específicos destinados a medirlos, algunos se miden en más de un reactivo. Además, la escala presenta algunos ítems complejos, puesto que miden principalmente un rasgo, pero indirectamente también pueden vincularse y medir otros principios penales.

\section{Confiabilidad y Validez de la EAPDP}

A continuación, resumimos las propiedades de confiabilidad y validez de la escala.

La EAPDP presenta adecuadas propiedades psicométricas a nivel exploratorio. Su estructura factorial fue establecida mediante AFE (utilizando Análisis Paralelo de Horn, Ejes Principales y Promax) encontrándose seis factores con cargas sobre 0,350 que explicaban un $45 \%$ de la varianza. Con ello, se evidencia que la escala posee adecuadas propiedades de validez exploratoria (que efectivamente la escala lograría medir la adhesión a los principios penales). Su confiabilidad fue establecida mediante coeficiente alfa de Cronbach, encontrándose valores cercanos al 0,7 o superiores para cada subescala. Esto último indica que la medición es precisa (con bajo nivel de error), que los ítems miden un mismo concepto y que cada uno de ellos aporta con información propia y diferenciada. A partir de esta información se construyeron seis subescalas y una Escala General de Adhesión que, de acuerdo a Fuentealba y Barriga ${ }^{38}$, fueron conceptualizadas del siguiente modo:

\section{Tabla 3}

Escala y subescalas de adhesión a los principios penales

\begin{tabular}{l|l}
\hline Variable al principio de & Concepto \\
\hline $\begin{array}{l}\text { Adhesión avel de consenso público en torno al principio que establece que las } \\
\text { gradualidad de la pena (8 ítems; } \\
\alpha=0,865) .\end{array}$ & $\begin{array}{l}\text { Nenas deben aplicarse de forma diferenciada, utilizando criterios de } \\
\text { graduación (o proporción), los cuales pueden ser esenciales (como la } \\
\text { culpabilidad y responsabilidad, que distingue entre dolo o culpa y que } \\
\text { pueden extinguir la responsabilidad penal) y/o accidentales } \\
\text { (vinculados a las atenuantes/agravantes, tales como irreprochable } \\
\text { conducta anterior, responsabilidad penal especial en el trato } \\
\text { diferenciado entre adultos y menores, reparación del daño causado, } \\
\text { colaboración del acusado, pero que no extinguen la responsabilidad } \\
\text { penal). Esta variable no mide proporcionalidad entendida como } \\
\text { relación de proporción entre la sanción y el valor del bien jurídico } \\
\text { afectado }\end{array}$ \\
\hline $\begin{array}{l}\text { Adhesión al principio del derecho } \\
\text { al debido proceso (12 preguntas; } ; \\
\alpha=0,797)\end{array}$ & $\begin{array}{l}\text { Nivel de consenso en torno al principio que establece que dentro del } \\
\text { juicio deben respetarse ciertas garantías de los acusados, tales como el } \\
\text { derecho a defensa, a jueces independientes e imparciales, la legalidad } \\
\text { en la obtención de la prueba, el principio de plena prueba y duda } \\
\text { razonable. Además, mide si se acepta la idea de que, una vez concluido } \\
\text { el proceso, la responsabilidad penal es personal, sin que la pena deba } \\
\text { trascender del sujeto que cometió el delito. }\end{array}$ \\
\hline
\end{tabular}

\footnotetext{
${ }^{38}$ FUENTEALBA/BARRIGA, "Primera aproximación”, cit. nota n²0.
} 


\begin{abstract}
Adhesión al principio de intervención mínima y legalidad en la aplicación de medidas y penas ( 8 preguntas; $\alpha=0,720$ ).
\end{abstract}

Nivel de consenso en torno al principio que establece que debe respetarse el rigor legal en la aplicación de medidas cautelares (opuestas a la presunción de inocencia) y de seguridad (basadas en el principio de peligrosidad). El rigor legal se establece por la presencia de reactivos vinculados indirectamente con el debido proceso (imparcialidad e independencia) y con el estándar probatorio (ítems 10 y 20). Finalmente, reactivos que miden el principio de subsidiariedad sancionatoria (14 y 40), permiten inferir que la población interpreta las medidas cautelares y de seguridad como sanciones penales

Adhesión al principio de
humanidad de las penas desde un
sistema estatal de justicia
preguntas; $\alpha=0,781)$.

Adhesión al principio de legalidad penal ( 6 preguntas; $\alpha=0,810$ ).

Nivel de consenso en torno a la legitimidad del rol del Estado como entidad con el derecho a concentrar y monopolizar la administración del ius puniendi, junto con las limitaciones básicas impuestas al ejercicio del poder estatal que establecen que las penas no pueden consistir en maltratos físicos, psicológicos, torturas ni tratos degradantes

Nivel de consenso en torno al principio que establece que delitos y penas deben encontrarse previamente establecidos por ley escrita (nullum crime, nulla poena sine praevia lege). Incluye la máxima taxatividad legal (que prescribe que la ley penal debe ser clara y precisa en oposición a las leyes en blanco), la máxima taxatividad interpretativa (que busca reducir la arbitrariedad del juez al exigir apego al texto legal y mínima interpretación, salvo que sea favorable al acusado o reo). Adicionalmente, mide el principio de Reserva Legal, ya que, en lo penal, sólo puede considerarse la ley emanada del congreso y no la opinión pública que no se ha expresado por la vía establecida constitucionalmente

Adhesión a los derechos sociales $\mathrm{y}$ de trato a condenados y acusados ( 8 preguntas; $\alpha=0,676$ ).

Escala General

(promedio de las 6 subescalas; $\alpha=0,753)$

Para construir cada subescala se promediaron sus respectivos ítems. Con la sumatoria de los puntajes de cada subescala se construyó la Escala General de adhesión. De esta forma, las comparaciones por grupo se efectuaron en función de las subescalas y de la escala general.

\section{Análisis de los datos}

\footnotetext{
${ }^{39}$ El uso del término "tratado" como inocente en los ítems 1 y 29, en vez del verbo considerar o "presumir", pudo incidir en que estos ítems cargasen en este factor y no en otro (como en el de Debido Proceso).
} 


\section{Polít. crim. Vol. 14, No 27 (Julio 2019), Art. 14, pp. 491-519 \\ [http://politcrim.com/wp-content/uploads/2019/05/Vol14N27A14.pdf]}

Para comparar los niveles de adhesión a los principios penales de acuerdo al perfil sociodemográfico y político se efectuaron análisis bivariados. Las comparaciones entre hombres y mujeres (2 grupos), se realizaron con la prueba t-Student que contrasta promedios entre dos grupos. Para comparar la adhesión de acuerdo al tramo etario (4 grupos), nivel educacional (4 grupos) y adscripción política (5 grupos) se utilizó ANOVA que permite comparar promedios entre tres o más categorías. Posteriormente, en ANOVA se utilizó la prueba post hoc (HSD Tukey y T2 de Tamhane) para identificar aquellos grupos entre los cuales se presentan las diferencias estadísticamente significativas. Finalmente, se utilizó R cuadrado corregido para estimar el tamaño del efecto.

Para el lector no familiarizado con nomenclatura estadística, señalamos que los asteriscos en las tablas indican que existen diferencias estadísticamente significativas entre los promedios de los grupos comparados (p.ej. entre hombres y mujeres) de acuerdo al test de hipótesis. Por lo tanto, ambas variables estarían relacionadas (p.ej. adhesión con sexo del entrevistado), y las diferencias entre promedios se deberían a una relación estadísticamente sistemática, y no a un vínculo azaroso. La probabilidad de que 'no' existan diferencias significativas entre los promedios se marca con un asterisco cuando es igual o menor al $5 \%$ (*), con dos asteriscos cuando ésta es inferior a $1 \%$ (**) y con tres asteriscos cuando es inferior al $0,1 \%(* * *)$. Inversamente, podemos interpretar que la probabilidad de que sí haya una diferencia significativa, sistemática (no azarosa y que no hayamos cometido un error) entre grupos es superior al $95 \%(*), 99 \%(* *)$ o $99,99 \%(* * *)$.

\section{Resultados}

\subsection{Adhesión a los principios penales diferenciada por sexo.}

A continuación, se compara la $A P D P$ entre hombres y mujeres con la prueba t-Student. Se presenta el $R$ corregido para determinar la fuerza de la diferencia.

\begin{tabular}{|c|c|c|c|c|}
\hline \multirow[t]{10}{*}{$\mathrm{Se}$} & \multicolumn{4}{|c|}{$\begin{array}{c}\text { Tabla } 4 \\
\text { Diferencias en la } \\
\text { adhesión a los principios penales por sexo }\end{array}$} \\
\hline & & $\begin{array}{c}\text { Hombres } \\
(\mathrm{n}=166)\end{array}$ & $\begin{array}{l}\text { Mujeres } \\
(\mathrm{n}=203)\end{array}$ & T-Student. \\
\hline & Adhesión al principio de... & $M / D E$ & $M / D E$ & $\begin{array}{c}\mathrm{R}^{2} \\
\text { corregido }\end{array}$ \\
\hline & Gradualidad de la pena & $2,68 / 0,951$ & $2,52 / 0,908$ & $0,005^{*}$ \\
\hline & Derecho al debido proceso & $3,52 / 0,686$ & $3,31 / 0,659$ & $0,020 * *$ \\
\hline & $\begin{array}{l}\text { Limitación y legalidad en la aplicación de } \\
\text { penas y medidas }\end{array}$ & 2,37/0,724 & $2,17 / 0,652$ & $0,018 * *$ \\
\hline & $\begin{array}{l}\text { Humanidad de las penas desde un sistema } \\
\text { estatal de justicia }\end{array}$ & $3,42 / 0,871$ & $3,28 / 0,881$ & 0,003 \\
\hline & Principio de legalidad penal & $2,82 / 0,978$ & $2,56 / 0,885$ & $0,016 * *$ \\
\hline & $\begin{array}{l}\text { Derechos sociales y de trato a acusados y } \\
\text { condenados. }\end{array}$ & $3,32 / 0,839$ & $3,18 / 0,761$ & $0,005 *$ \\
\hline & Escala general $A P D P$ & $3,02 / 0,572$ & $2,83 / 0,521$ & $0,025 * * *$ \\
\hline
\end{tabular}

observan diferencias significativas entre hombres y mujeres en cinco sub-escalas y, además, 
en la Escala General (puesto que presentan un valor $p$ inferior a 0,05). Los datos muestran que los hombres tienden a presentar mayores niveles de adhesión promedio que las mujeres. Sin embargo, la variabilidad explicada sería de entre un $2,5 \%\left(R^{2}=0,025\right)$ y un $0,5 \%$ $\left(\mathrm{R}^{2}=0,005\right)$, lo cual permitiría comprender el hecho de que estas diferencias promedio sean leves (Tabla 4).

\subsection{Adhesión a los principios penales diferenciada por tramo etario.}

A continuación, se comparan los niveles de APDP de acuerdo al tramo etario con la prueba ANOVA. Se generaron cuatro grupos como tramos etarios.

Tabla 5

Diferencias en la

adhesión a los principios penales por tramo etario

\begin{tabular}{|c|c|c|c|c|c|}
\hline & $\begin{array}{c}18-29 \\
(\mathrm{n}=187)\end{array}$ & $\begin{array}{l}30-45 \\
(\mathrm{n}=72)\end{array}$ & $\begin{array}{l}46-59 \\
(n=79)\end{array}$ & $\begin{array}{l}60 \text { o más } \\
(\mathrm{n}=31)\end{array}$ & ANOVA \\
\hline Adhesión al principio de... & $M / D E$ & $M / D E$ & $M / D E$ & $M / D E$ & $p$ \\
\hline Gradualidad de la pena & $2,58 / 0,867$ & $2,69 / 1,039$ & $2,47 / 0,993$ & $2,64 / 0,866$ & 0,542 \\
\hline Derecho al debido proceso & $3,44 / 0,649$ & $3,45 / 0,724$ & $3,29 / 0,697$ & $3,25 / 0,670$ & 0,191 \\
\hline $\begin{array}{l}\text { Limitación y legalidad en la } \\
\text { aplicación de penas y medidas }\end{array}$ & $2,33 / 0,668$ & $2,22 / 0,760$ & $2,14 / 0,700$ & $2,18 / 0,614$ & 0,174 \\
\hline $\begin{array}{l}\text { Humanidad de las penas desde un } \\
\text { sistema estatal de justicia }\end{array}$ & $3,29 / 0,864$ & $3,38 / 0,875$ & $3,40 / 0,885$ & $3,34 / 0,969$ & 0,768 \\
\hline Principio de legalidad penal & $2,70 / 0,921$ & $2,84 / 0,960$ & $2,47 / 0,977$ & $2,62 / 0,788$ & 0,100 \\
\hline $\begin{array}{l}\text { Derechos sociales y de trato a } \\
\text { acusados y condenados. }\end{array}$ & $3,21 / 0,807$ & $3,26 / 0,798$ & $3,25 / 0,816$ & $3,36 / 0,730$ & 0,791 \\
\hline Escala general $A P D P$ & $2,93 / 0,543$ & $2,98 / 0,549$ & $2,84 / 0,586$ & $2,91 / 0,552$ & 0,482 \\
\hline
\end{tabular}

$* \mathrm{P}<0,05 * *$ P $<0,01 \quad * * * \mathrm{P}<0,001$ (bilateral)

No se encontraron diferencias significativas entre los grupos etarios (valores $p$ fueron superiores a 0,05), por lo cual no se efectuaron pruebas post hoc. Esto indicaría que la adhesión a los principios penales no variaría de acuerdo al segmento etario, sino que se encontraría generalizada, siendo homogénea (Tabla 5).

\section{3.- Adhesión a los principios penales diferenciada por nivel educacional.}

La tabla siguiente compara la $A P D P$ de acuerdo al Nivel Educacional dividido en cuatro niveles. Se utilizó la prueba ANOVA y se presenta el $\mathrm{R}^{2}$ corregido para establecer la fuerza de las diferencias. 
Tabla 6.1.

Diferencias en la adhesión a los principios penales por nivel educacional

\begin{tabular}{|c|c|c|c|c|c|}
\hline & $\begin{array}{c}\text { S/estudios } \\
\text { hasta Media } \\
\text { Compl. } \\
(\mathrm{n}=96) \\
\text { (A) }\end{array}$ & $\begin{array}{l}\text { Técnica-Prof. } \\
\text { Incompl. } \\
(\mathrm{n}=60) \\
\text { (B) }\end{array}$ & $\begin{array}{l}\text { Prof. Compl. } \\
\text { o Univ. } \\
\text { Incompl. } \\
(\mathrm{n}=109) \\
(\mathrm{C})\end{array}$ & $\begin{array}{c}\text { Univ. } \\
\text { Completa } \\
(\mathrm{n}=104) \\
(\mathrm{D})\end{array}$ & ANOVA \\
\hline Adhesión al principio de... & $M / D S$ & $M / D S$ & $M / D S$ & $M / D S$ & $\begin{array}{c}\mathrm{R}^{2} \\
\text { correg. }\end{array}$ \\
\hline Gradualidad de la pena & $2,47 / 0,871$ & $2,49 / 0,973$ & $2,59 / 0,917$ & $2,75 / 0,959$ & 0,007 \\
\hline Derecho al debido proceso & $3,16 / 0,603$ & $3,19 / 0,638$ & $3,51 / 0,690$ & $3,63 / 0,656$ & $0,082 * * *$ \\
\hline $\begin{array}{l}\text { Limitación y legalidad en la } \\
\text { aplicación de penas y medidas }\end{array}$ & $2,23 / 0,689$ & $2,17 / 0,676$ & $2,26 / 0,720$ & $2,34 / 0,675$ & 0,001 \\
\hline $\begin{array}{l}\text { Humanidad de las penas desde un } \\
\text { sistema estatal de justicia }\end{array}$ & $3,26 / 0,957$ & $3,26 / 0,857$ & $3,34 / 0,858$ & $3,46 / 0,832$ & 0,000 \\
\hline Principio de legalidad penal & $2,38 / 0,841$ & $2,60 / 0,879$ & $2,79 / 0,942$ & $2,88 / 0,981$ & $0,036 * * *$ \\
\hline $\begin{array}{l}\text { Derechos sociales y de trato a } \\
\text { acusados y condenados. }\end{array}$ & $3,25 / 0,788$ & $3,15 / 0,720$ & $3,21 / 0,826$ & $3,33 / 0,827$ & 0,003 \\
\hline Escala general $A P D P$ & $2,79 / 0,522$ & $2,81 / 0,466$ & $2,95 / 0,564$ & $3,06 / 0,579$ & $0,033 * *$ \\
\hline
\end{tabular}

$* \mathrm{P}<0,05 \quad * * \mathrm{P}<0,01 \quad * * * \mathrm{P}<0,001$ (significancia bilateral)

La Tabla 6.1 muestra que existen diferencias significativas en la intensidad del apoyo a los principios penales en dos subescalas y en la escala general de acuerdo al nivel educacional (valores $p$ inferiores a 0,05 ). La tendencia general indica que los sujetos con mejores niveles educacionales presentan niveles de adhesión promedio más altos que quienes poseen niveles educacionales más bajos. El nivel educacional explicaría entre el 8,2\% $\left(\mathrm{R}^{2}=0,082\right)$ y el 3,3\% $\left(\mathrm{R}^{2}=0,033\right)$ de la variabilidad, el cual no es un rango especialmente alto, pero tampoco despreciable.

Tabla 6.2.

Comparación entre grupos

\begin{tabular}{|c|c|c|}
\hline \multicolumn{3}{|c|}{ (HSD Tukey) } \\
\hline $\begin{array}{c}\text { Derecho al debido } \\
\text { proceso y personalidad } \\
\text { de la pena. }\end{array}$ & $\begin{array}{c}\text { Principio de } \\
\text { legalidad } \\
\text { penal }\end{array}$ & $\begin{array}{c}\text { Escala General } \\
\text { de } \\
A P D P \\
\end{array}$ \\
\hline $\mathrm{A}-\mathrm{B}$ & A-B & A-B \\
\hline $\mathrm{A}-\mathrm{C} * * *$ & $\mathrm{~A}-\mathrm{C} * *$ & $\mathrm{~A}-\mathrm{C}$ \\
\hline A-D*** & $\mathrm{A}-\mathrm{D} * * *$ & A-D** \\
\hline $\mathrm{B}-\mathrm{C} * * *$ & $\mathrm{~B}-\mathrm{C}$ & $\mathrm{B}-\mathrm{C}$ \\
\hline $\mathrm{B}-\mathrm{D} * * *$ & B-D & $\mathrm{B}-\mathrm{D} * *$ \\
\hline C-D & C-D & C-D \\
\hline
\end{tabular}

La prueba post hoc HSD Tukey (Tabla 6.2) muestra los grupos específicos entre los cuales se producen las diferencias significativas.

Se observa que, en la Adhesión al derecho al debido proceso (primera columna), existen diferencias significativas entre medias ( $p$ inferior a 0,05) en la mayor parte de las comparaciones entre grupos. Primero, se observan diferencias significativas entre el grupo A (Sin Estudios hasta Enseñanza Media Completa) con los grupos C (Profesional Completa o Universitaria Incompleta) y D (Universitaria Completa o más). Segundo, se observan 
diferencias significativas entre el grupo B (Técnica Incompleta/Completa o Profesional Incompleta) con los grupos C (Profesional Completa o Universitaria Incompleta) y D (Universitaria Completa o más). Al observar las medias (Tabla 4.1), encontramos que los grupos con mejores niveles educacionales $(\mathrm{C}$ y $\mathrm{D})$, serían los que tienen promedios de adhesión más altos. En cambio, quienes tienen niveles educacionales más bajos (A y B) serían los que presentan promedios de adhesión más bajas (Tabla 4.1). Entre el resto de las categorías comparadas no se encontraron diferencias significativas, lo cual refleja que entre éstas existen niveles similares de apoyo a los principios medidos.

En la Adhesión al principio de legalidad penal (segunda columna), se muestran diferencias significativas de medias en la menor parte de los grupos comparados. Primero, se estableció que las diferencias se presentan entre el grupo A (Sin Estudios hasta Enseñanza Media Completa) con los grupos C (Profesional Completa o Universitaria Incompleta) y D (Universitaria Completa o más). Al observar las medias (Tabla 4.1), se aprecia que los grupos con mejores niveles educacionales (C y D) serían los que cuentan con promedios de adhesión más altos, mientras que el grupo con menores niveles educacionales (A) sería el que tiene promedios más bajos. Entre el resto de los grupos existiría cierta homogeneidad en la intensidad de la adhesión, puesto que no se observaron diferencias estadísticamente significativas entre los promedios.

En la Escala General de APDP (tercera columna), la prueba muestra diferencias significativas entre medias en la menor parte de las comparaciones entre grupos. Las diferencias se presentaron entre el grupo D (Universitaria Completa o más) con los grupos A (Sin Estudios hasta Enseñanza Media Completa) y B (Técnica Incompleta/Completa o Profesional Incompleta). Al observarse las medias (Tabla 4.2), se encuentra que el grupo con mejores niveles educacionales (D) sería el que presenta medias más altas en la adhesión, mientras que los grupos con más bajos niveles educativos (A y B) serían los que presentan medias más bajas.

En resumen, es posible apreciar que los individuos que poseen mejores niveles educacionales ( $\mathrm{C}$ y D), son los que tienden a presentar mayores niveles de adhesión a los principios penales, ya sea en la escala general o en algunas de sus subescalas. En cambio, las personas que tienen niveles educacionales más bajos (A y B), serían quienes tienden a exhibir menores niveles de adhesión.

\subsection{Adhesión a los principios penales diferenciada por adscripción política.}

A continuación, se compara la $A P D P$ de acuerdo a la adscripción política. Se utilizó la prueba ANOVA y se presenta el $\mathrm{R}^{2}$ corregido para determinar la fuerza de la diferencia. Considerando que existía un grupo (Derecha) que poseía menos de 30 casos, los datos fueron confirmados con la prueba $\mathrm{H}$ de Kruskal-Wallis. 
Tabla 7.1.

Diferencias en la adhesión a los principios penales por adscripción política

\begin{tabular}{|c|c|c|c|c|c|c|}
\hline & $\begin{array}{l}\text { Izquierda } \\
(\mathrm{n}=46) \\
\text { (A) }\end{array}$ & $\begin{array}{l}\text { Centro izquierda } \\
\qquad(\mathrm{n}=51) \\
\text { (B) }\end{array}$ & $\begin{array}{c}\text { Centro } \\
(\mathrm{n}=190) \\
(\mathrm{C})\end{array}$ & $\begin{array}{l}\text { Centro Derecha } \\
(\mathrm{n}=31) \\
\text { (D) }\end{array}$ & $\begin{array}{c}\text { Derecha } \\
(\mathrm{n}=17) \\
(\mathrm{E})\end{array}$ & ANOVA \\
\hline General & $M / D S$ & $M / D S$ & $M / D S$ & $M / D S$ & $M / D S$ & $\begin{array}{c}\mathrm{R}^{2} \\
\text { correg }\end{array}$ \\
\hline Gradualidad de la pena & $2,64 / 1,025$ & $2,73 / 0,950$ & $2,51 / 0,837$ & $2,51 / 0,834$ & $2,40 / 0,876$ & $-0,003$ \\
\hline Derecho al debido proceso & $3,50 / 0,794$ & $3,58 / 0,610$ & $3,37 / 0,734$ & $3,56 / 0,553$ & $3,26 / 0,615$ & 0,008 \\
\hline $\begin{array}{l}\text { Limitación y legalidad en } \\
\text { la aplicación de penas y } \\
\text { medidas }\end{array}$ & $2,54 / 0,849$ & $2,39 / 0,663$ & $2,18 / 0,518$ & $2,25 / 0,535$ & $2,11 / 0,634$ & $0,024 *$ \\
\hline $\begin{array}{l}\text { Humanidad de las penas } \\
\text { desde un sistema estatal de } \\
\text { justicia }\end{array}$ & $3,52 / 0,919$ & $3,65 / 0,814$ & $3,34 / 0,809$ & $3,29 / 0,658$ & $2,78 / 0,809$ & $0,031 * *$ \\
\hline $\begin{array}{l}\text { Principio de legalidad } \\
\text { penal }\end{array}$ & $2,83 / 1,113$ & $2,99 / 0,932$ & $2,65 / 0,903$ & $2,54 / 0,746$ & $2,50 / 0,951$ & 0,012 \\
\hline $\begin{array}{l}\text { Derechos sociales y de } \\
\text { trato a acusados y } \\
\text { condenados. }\end{array}$ & $3,42 / 0,906$ & $3,43 / 0,625$ & $3,18 / 0,667$ & $3,22 / 0,663$ & $2,87 / 0,015$ & $0,017 *$ \\
\hline Escala general $A P D P$ & $3,07 / 0,704$ & $3,13 / 0,557$ & $2,87 / 0,507$ & $2,89 / 0,301$ & $2,65 / 0,545$ & $0,035 * *$ \\
\hline
\end{tabular}

La Tabla 7.1 muestra que existen diferencias significativas en los niveles de adhesión a los principios penales de acuerdo a la adscripción política en dos subescalas y en la Escala General (valores $p$ inferiores a 0,05). La tendencia general muestra que las personas con adscripción política de derecha presentan niveles de adhesión promedio más bajos hacia los principios que las personas de centro izquierda. Sin embargo, esta relación no es especialmente consistente ni clara. La adscripción política del entrevistado explicaría entre el $3,5 \%\left(R^{2}=0,035\right)$ y el $1,7 \%\left(R^{2}=0,017\right)$ de la variabilidad, el cual no es un rango especialmente alto, pero permite afirmar la existencia de cierta asociación entre estas variables.

Tabla 7.2.

Comparación entre grupos (HSD Tukey y T2 de Tamhane)

\begin{tabular}{cccc}
$\begin{array}{c}\text { Limitación y legalidad } \\
\text { en la aplicación de penas } \\
\text { y medidas. }\end{array}$ & $\begin{array}{c}\text { Humanidad de las } \\
\text { penas desde un } \\
\text { sistema estatal de } \\
\text { justicia. }\end{array}$ & $\begin{array}{c}\text { Derechos de } \\
\text { sociales y de trato a } \\
\text { acusados y } \\
\text { condenados. }\end{array}$ & $\begin{array}{c}\text { Escala General de } \\
\text { APDP. }\end{array}$ \\
\hline A-B & A-B & A-B & A-B \\
A-C** & A-C & A-C & A-C \\
A-D & A-D & A-D & A-D \\
A-E & A-E* & A-E & A-E* \\
B-C & B-C & B-C & B-C* \\
B-D & B-D & B-D & B-D \\
\hline
\end{tabular}



sociedad? Estudio piloto en el Gran Concepción, Chile.

\begin{tabular}{llll}
\hline B-E & B-E* & B-E* & B-E* \\
C-D & C-D & C-D & C-D \\
C-E & C-E* & C-E & C-E \\
D-E & D-E & D-E & D-E \\
\hline
\end{tabular}

$* \mathrm{P}<0,05 \quad * * \mathrm{P}<0,01 \quad * * * \mathrm{P}<0,001$ (bilateral)

Las pruebas post hoc HSD Tukey y T2 de Tamhane (Tabla 7.2) muestran los grupos específicos entre los cuales se producen las diferencias significativas.

En la subescala de Adhesión a la Limitación y Legalidad en la Aplicación de Penas y Medidas, las diferencias se producirían entre el grupo adscrito a la Izquierda (A) con el de Centro (C), donde las personas de izquierda serían quienes poseen mayores niveles de adhesión. En el resto de los grupos se observaría cierta homogeneidad en la adhesión promedio.

En la Adhesión al Principio de Humanidad de las Penas desde un Sistema Estatal de Justicia, se observan diferencias significativas entre las personas con adscripción política de Derecha (E) con las personas de Izquierda (A), Centro-Izquierda (B) y Centro (C), donde las personas identificadas con la derecha presentarían menores niveles promedio de adhesión a esta dimensión de los principios penales. No se observaron diferencias entre el resto de las comparaciones múltiples.

En la Adhesión a los derechos sociales y de trato a los acusados y condenados, sólo se observan diferencias entre las personas adscritas a la Derecha (E) con la Centro-Izquierda (B), donde los adscritos a la Derecha exhibirían menores niveles promedio de apoyo a esta dimensión de la adhesión a los principios penales. El resto de los grupos serían relativamente homogéneos, sin presentar diferencias.

Finalmente, al comparar en la Escala General de Adhesión a los Principios Penales $(E A P D P)$, se observa una diferencia entre quienes adscriben a la Derecha $(\mathrm{E})$ con quienes adscriben a la Izquierda (A) y Centro Izquierda (B), donde las personas de derecha serían quienes presentarían menores niveles de apoyo promedio frente a los principios penales. Además, se aprecian diferencias entre las personas de Centro Izquierda (B) con las personas de Centro (C). De entre estos dos grupos, las personas de centro serían quienes presentan menores niveles promedio de apoyo ante los principios penales en general y los de izquierda mayores. En el resto de grupos los niveles de adhesión serían relativamente homogéneos, puesto que no se observan diferencias estadísticamente significativas.

\section{Discusión}

Sin perjuicio de las limitaciones que presenta el estudio, los resultados han mostrado la existencia de importantes relaciones entre las variables estudiadas. Los hallazgos nos permiten afirmar que hay un apoyo de las hipótesis $H_{1}, H_{3}, H_{4}$, ya que las mujeres, las personas con menores niveles educacionales y las personas con adscripción política de derecha presentarían una menor intensidad en la adhesión a los principios penales, lo cual indicaría que estas variables estarían relacionadas. Sin embargo, debe precisarse que el 
apoyo a las hipótesis es más bien parcial, ya que las diferencias observadas no son especialmente fuertes ni tampoco muy consistentes, porque no se presentaron en todas las dimensiones de la adhesión ni en todos los grupos comparados mediante las pruebas post hoc. Finalmente, no se observaron diferencias en la intensidad de la adhesión de acuerdo al tramo etario $\left(\mathrm{H}_{2}\right)$, lo cual indicaría que edad y adhesión al parecer no se relacionan.

El que las mujeres presenten menores niveles de adhesión a los principios penales, puede comprenderse por el hecho de que éstas tienden a presentar mayores niveles de miedo al delito que los hombres. Las mujeres se perciben más débiles y vulnerables que los hombres y consideran que poseen menores recursos para defenderse frente al delito ${ }^{40}$. Cualquier tipo de delito (p.ej. robo) puede derivar en un delito sexual, por lo que su miedo a ser víctima de este tipo de delitos se extendería a su miedo a ser víctima de delito en general ${ }^{41}$. Estas creencias estarían fundadas tanto en la experiencia directa o indirecta (que algunas mujeres hayan enfrentado o conozcan casos cercanos de mujeres que enfrentaron situaciones de vulnerabilidad ante el delito) como en el proceso de aprendizaje cultural, que se desarrolla a partir de la socialización por roles de género transmitida por la familia ${ }^{42}$ y también por las representaciones transmitidas por los medios de comunicación, que habitualmente exponen a las mujeres como víctimas de la delincuencia en noticieros y series de televisión. Al presentar mayores niveles de miedo al delito, tendrían un menor grado de apoyo a los principios penales ${ }^{43}$, porque las garantías y derechos derivados de estos principios serían concebidos, tal vez, como limitaciones para las funciones de seguridad pública (donde el castigo puede ser concebido como disuasivo), contribuyendo a la sensación de desprotección frente al delito.

En lo que respecta a la edad, se esperaba que las personas de tramos etarios más altos presentasen menores niveles de adhesión $\left(\mathrm{H}_{2}\right)$. Esta expectativa estaba fundada, por un lado, en el hecho de que las personas mayores poseen mayores niveles de miedo al delito por sentirse más vulnerables físicamente ${ }^{44} \mathrm{y}$, por otro, por el hecho de que la adhesión a los principios penales disminuye cuando hay mayor percepción de inseguridad ${ }^{45}$. El que los datos no hayan apoyado esta hipótesis puede explicarse por el hecho de que la literatura es también inconsistente en cuanto a la relación entre edad y miedo al delito, dado que algunas investigaciones han evidenciado que los jóvenes poseen mayores niveles de miedo al delito (porque se exponen a más situaciones de riesgo) ${ }^{46}$, otras no han encontrado evidencia de esta

\footnotetext{
${ }^{40}$ FRANKLIN, Cortney A.; FRANKLIN, Travis W., "Predicting fear of crime: Considering differences across gender", Feminist Criminology, vol. 4, n 1 (2009), pp. 83-106; RADER/HAYNES, “Gendered fear of crime socialization", cit. nota $n^{\circ} 11$; RADER, "Fear of Crime", cit. nota $n^{\circ} 10$.

${ }^{41}$ HENSON/REYNS "The Only Thing", cit. nota ${ }^{\circ} 8$; RADER/HAYNES, "Gendered fear of crime socialization", cit. nota $n^{\circ} 11$; RADER, "Fear of Crime", cit. nota $n^{\circ} 10$.

${ }^{42}$ RADER/HAYNES, "Gendered fear of crime socialization", cit. nota ${ }^{\circ} 11$.

${ }^{43}$ FUENTEALBA/BARRIGA, "Primera aproximación”, cit. nota n 20.

${ }^{44}$ GIBSON, Chris L.; ZHAO, Jihong; LOVRICH, Nicholas P.; GAFFNEY, Michael J., "Social Integration, Individual Perceptions of Collective Efficacy, and Fear of Crime in Three Cities", Justice Quarterly, vol. 19, $\mathrm{n}^{\circ} 3$ (2002), pp. 537-564.

${ }^{45}$ FUENTEALBA/BARRIGA, "Primera aproximación”, cit. nota $n^{\circ} 20$.

${ }^{46}$ FRANKLIN, Travis W.; FRANKLIN, Cortney A.; FEARN, Noelle E., "A Multilevel Analysis of the Vulnerability, Disorder, and Social Integration Models of Fear of Crime", Social Justice Research, vol. 21, ${ }^{\circ}$ 2 (2008), pp. 204-227; ROUNTREE, Pamela W.; LAND, Kenneth C., "Perceived Risk versus Fear of Crime:
} 
relación ${ }^{47}$ y otras han señalado que la relación entre edad y miedo al delito está sujeta a la influencia de otras variables o a la forma en que es medido este fenómeno ${ }^{48}$.

Las personas con menores niveles educacionales apoyarían menos el conjunto de principios penales, lo que podría comprenderse por tres razones principales. Primero (1), quienes poseen niveles educativos más bajos (especialmente educación técnica, profesional incompleta, o enseñanza media) presentarían mayores niveles de miedo al delito. Esto, porque aquellos grupos serían quienes poseen ingresos más bajos que no les permiten vivir en barrios y entornos más seguros ${ }^{49}$ y porque estos grupos serían más sensibles a la información sobre criminalidad entregada por los medios de comunicación, al estar en contacto directo con los problemas delictuales de sus barrios o entornos, lo que estaría en línea con la perspectiva de la resonancia ${ }^{50}$. Así, el mayor miedo al delito influiría negativamente en el apoyo a los principios penales, dado que percibirían una mayor amenaza y, por lo tanto, considerarían a los principios penales instrumentalmente como trabas a las funciones de seguridad del Estado ${ }^{51}$. Segundo (2), los sujetos con menores niveles educativos han tenido una experiencia cultural diferente (tal vez carente de contenidos conceptuales, teóricos o doctrinales) a la que se proporciona principalmente en los niveles terciarios. En el nivel terciario, los entrevistados pueden adquirir ciertos conocimientos vinculados con estos principios penales a través de cursos formales (p.ej. Derecho, Ética, Derechos Humanos, Filosofía, etc.), sin que necesariamente hayan cursado la carrera de Derecho, ya que estos conocimientos pueden adquirirse a través de la formación general recibida en una carrera. Asimismo, la educación puede incrementar la capacidad de abstracción necesaria para poder comprender de mejor forma principios de este

Empirical Evidence of Conceptually Distinct Reactions in Survey Data”, Social Forces, vol. 74, n 4 (1996), pp. 1353-1376.

${ }^{47}$ ALPER, Mariel; CHAPPELL, Allison T., "Untangling Fear of Crime: A Multi-theoretical Approach to Examining the Causes of Crime-Specific Fear", Sociological Spectrum: Mid-South Sociological Association, vol. 32, n 4 (2012), pp. 346-363; DAMMERT, Lucía; MALONE, Mary Fran T., "Fear of Crime or Fear of Life? Public Insecurities in Chile", Bulletin of Latin American Research, vol. 22, n 1 (2003), pp. 79-101; DAMMERT, Lucía; MALONE, Mary Fran T., "Does It Take a Village? Policing Strategies and Fear of Crime in Latin America", Latin American Politics and Society, vol. 48, n 4 (2006), pp. 27-51; RADER, Nicole E.; MAY, David C.; GOODRUM, Sarah, "An Empirical Assesment of the "Threat of Victimization": Considering Fear of Crime, Perceived Risks, Avoidance, and Defensive Behaviours", Sociological Spectrum: Mid-South Sociological Association, vol. 27, $\mathrm{n}^{\circ} 5$ (2007), pp. 475-505.

${ }^{48}$ BEAULIEU/DUBÉ/BERGERON/COUSINEAU, “Are elderly men”, cit. nota $n^{\circ} 12$; DE DONDER, Liesbeth; VERTÉ, Dominique; MESSELLIS, Els, "Fear of crime and elderly people: Key factors that determine fear of crime among elderly people in West Flanders", Aging International, vol. 30, $\mathrm{n}^{\circ} 4$ (2005), pp. 363-376; LAGRANGE/FERRARO, "Assessing Age and Gender", cit. nota n ${ }^{\circ} 11$; TULLOCH, Marian, "The Meaning of Age Differences in the Fear of Crime. Combining Quantitative and Qualitative Approaches", British Journal of Criminology, vol. 40, $\mathrm{n}^{\circ} 3$ (2000), pp. 451-467.

${ }^{49}$ COVINGTON Jeanette; TAYLOR, Ralph B., "Fear of Crime in Urban Residential Neighborhoods: Implications of Between- and Within-Neighborhood Sources for Current Models", The Sociological Quarterly, vol. 32, n 2 (1991), pp. 231-249; FRANKLIN/FRANKLIN, "Predicting fear of crime", cit. nota n 40 HALE, "Fear of crime", cit. nota ${ }^{\circ} 12$.

50 CALLANAN/ROSENBERGER "Media, Gender", cit. nota $\mathrm{n}^{\circ}$ 18; KOHM/WAID LINDBERG/WEINRATH/O'CONNOR-SHELLEY/DOBBS, "The Impact of Media”, cit. nota ${ }^{\circ} 18$.

${ }^{51}$ FUENTEALBA/BARRIGA, "Primera aproximación”, cit. nota nº 20. 
orden. Desde la teoría del capital cultural de Bourdieu ${ }^{52}$, eso permitiría desarrollar una suerte de capital jurídico y cultural básico o suficiente para comprender, aunque sea inicialmente, la racionalidad de estos principios y, así, adherir a éstos. Sin embargo, este capital cultural o cultura jurídica básica necesaria para entender mejor los principios, no se adquiriría en niveles primarios, secundarios y/o técnicos, lo cual explicaría que personas con niveles educacionales más bajos presenten una menor adhesión.

Las personas con ideologías de derecha (conservadores, liberales y que apoyaron la dictadura de Pinochet) tienden a ser más punitivas, por cuál tenderían a apoyar menos los principios penales, aunque por diversos motivos. Desde el eje valórico liberal-conservador, para las personas más conservadores, el castigo representaría simbólicamente una afirmación del consenso y del orden social establecido, donde los principios penales constituirían limitaciones para el poder punitivo estatal; considerarían que el delito constituye una amenaza para el orden social y el consenso normativo, para la convención y forma de vida tradicional, percibiendo al crimen como amenazante. Por ello, preferirían tener un sistema que mantenga el orden, aunque implique afectar libertades civiles. Desde un eje económico capitalismo-socialismo (bienestarismo), las personas de derecha considerarían que el delito constituye una amenaza para el orden desigual y jerárquico de la sociedad, basado en el sistema de clases, por lo cual el castigo se dirigiría especialmente contra la delincuencia común que prevalece mayormente en las clases más desfavorecidas. Asimismo, dada la visión más individualista del capitalismo, la estructura social desigual o la falta de igualdad de oportunidades no tendrían parte de la responsabilidad en el delito, sino que éste sería entendido como una decisión individual. Así, para bajo una imagen de sociedad conservadora en lo valórico y capitalistas en lo económico, el castigo representaría simbólicamente un respaldo al statu quo, lo cual permitiría tender personas de derecha tiendan a apoyar menos aquellos principios limitadores del ius puniendi (al menos frente a la delincuencia común) y prefieran un Estado capaz de castigar sin trabas. Este hallazgo sería consistente con la literatura sobre punitivismo, que muestra que las ideologías de derecha, más conservadoras y autoritarias tienden a apoyar en mayor medida las políticas punitivas, tales como la pena de muerte y el endurecimiento de las penas, a mostrar menor empatía con los delincuentes, mayor disposición al refuerzo del trabajo policial e, incluso, apoyar intervenciones militares ${ }^{53}$.

El hecho de que la relación entre ideología y adhesión no sea tan fuerte ni consistente podría explicarse por el hecho de que se no se haya empleado una escala multi-ítem para medir ideología política del entrevistado de forma precisa (tales como las de Social Domination Orientation (SDO) o Right-wing autoritarianism (RWA) empleadas en otras investigaciones) sino a través de una única pregunta de autoidentificación, el que podría ser un indicador impreciso. Por otra parte, en términos muestrales, las personas entrevistadas en la categoría derecha son sólo 17, lo cual pudo afectar la sensibilidad de las pruebas estadísticas (y p.ej. no encontrarse una asociación dado el bajo número de casos en este grupo). Por ello, sería

\footnotetext{
${ }^{52}$ BOURDIEU, Pierre; TEUNBER, Gunther, La Fuerza del Derecho, Colombia: Ediciones Uniandes, 2000.

${ }^{53}$ COLÉMONT/VAN HIEL/CORNELIS, "Five-Factor Model", cit. nota ${ }^{\circ}$ 24; GERBER/JACKSON, "Justifying violence", cit. nota $\mathrm{n}^{\circ}$ 15; SIDANIUS/MITCHELL/HALLEY/NAVARRETE, "Support for harsh criminal sanctions", cit. nota $\mathrm{n}^{\circ} 24$.
} 
interesante que nuevas investigaciones estudien la relación entre ideología y adhesión de forma más robusta.

\section{Conclusiones}

Uno de los principales hallazgos de la investigación es que la intensidad en la adhesión a los principios del derecho penal y procesal penal en la población estudiada no es homogénea, ya que varía de acuerdo al perfil sociodemográfico. Así, serían las mujeres, las personas con niveles educacionales más bajos y las personas con orientación política de derecha, las que presentarían los menores niveles de adhesión a estos principios, evidenciando que el sexo, la educación y la ideología política estarían relacionados con la adhesión. No se observó que la adhesión variase de acuerdo al tramo etario, lo cual permite pensar que la edad y la adhesión no son variables relacionadas.

Estos hallazgos tendrían coherencia con la amplia literatura sobre miedo al delito y punitivismo, pero, además, consideramos que contribuyen a ampliar el conocimiento sobre el ámbito particular de las actitudes punitivas. De esta forma, este trabajo ha empleado indicadores vinculados a la etapa del castigo, que serían equiparables a los usualmente empleados para conocer estas actitudes, pero también ha evaluado las condiciones carcelarias, la legalidad y el debido proceso, que no constituyen indicadores empleados en las investigaciones tradicionales en torno al tema, y menos bajo una medición multidimensional que intente integrar estos aspectos. La importancia de estas nuevas dimensiones se encuentra en que poseerían implicancias para el castigo. Por ello, un bajo apoyo ciudadano al debido proceso, a la legalidad, a las condiciones carcelarias, podría repercutir en la presión social (desde la opinión pública) por la eliminación de estas garantías, y así, en un mayor punitivismo estatal. En este punto creemos que radica el principal aporte disciplinar de nuestro trabajo que, de algún modo, posee ciertas características exploratorios.

La identificación de aquellos grupos en los cuales se focalizan con mayor o menor intensidad los niveles de adhesión a los principios, posee también alcances prácticos. Posteriores confirmaciones de estos hallazgos podrían contribuir como guías para la orientación de políticas públicas focalizadas en los grupos críticos identificados, las que podrían orientarse a mejorar los niveles de apoyo a estos principios para evitar así consecuencias punitivas. Sin embargo, cualquier política en esta dirección debiese requerir nuevos estudios que repliquen estos hallazgos en nuevos contextos (con alcance nacional), mediante muestras probabilísticas, análisis multivariados que permitan identificar otras variables predictoras e, incluso, complementarse mediante investigación cualitativa. Estamos muy entusiasmados con avanzar en la profundización de este aspecto del punitivismo y nuestros próximos esfuerzos ya se orientan en esa dirección. Por ello, con independencia de las limitaciones de este trabajo, creemos estar proporcionando la primera información bivariada o correlacional en torno a este tema. 


\section{Bibliografía}

ARMBORST, Andreas, "How fear of crime affects punitive attitudes", European Journal of Criminal policy and research, vol. 23, no 3 (2017), pp. 461-481.

AIZPURÚA, Eva; FERNÁNDEZ-MOLINA, Ester, "Información, ¿antídoto frente al populismo punitivo? Estudio sobre las actitudes hacia el castigo de los menores infractores y el sistema Judicial Juvenil, Revista Española de Investigación Criminológica, $\mathrm{n}^{\circ} 9$ (2011), A3, pp. 1-29.

ALPER, Mariel; CHAPPELL, Allison T., "Untangling Fear of Crime: A Multi-theoretical Approach to Examining the Causes of Crime-Specific Fear", Sociological Spectrum: Mid-South Sociological Association, vol. 32, n 4 (2012), pp. 346-363.

ALTMAN, David; LUNA, Juan Pablo; PIÑEIRO, Rafael; TORO, Sergio, "Partidos y sistemas de partidos en América Latina: Aproximaciones desde la encuesta a expertos 2009”, Revista de Ciencia Política, No. Vol. (2009) pp. 775-798.

AMAYA, Laura; ESPINOSA, Agustín; VOZMEDIANO, Laura, "Relaciones entre el Miedo al delito y el Autoritarismo de Derecha en estudiantes universitarios de Lima-Perú", Boletín de Psicología, 103 (2011), pp. 7-28.

BACIGALUPO, Enrique, Derecho Penal y el Estado de Derecho, Santiago: Editorial Jurídica de Chile, 2005.

BEAUlIEU, Marie; DUBÉ, Micheline; BERGERON, Christian; COUSINEAU, Marie Marthe, “Are elderly men worried about crime?", Journal of Aging Studies, vol. 21, $n^{\circ} 4$ (2007), pp. 336-346.

BOURDIEU, Pierre; TEUNBER, Gunther, La Fuerza del Derecho, Colombia: Ediciones Uniandes, 2000.

BROWNE, Magdalena; TOMICIC, Vinsja, "Crimen y temor, el rol de los medios", Cuadernos.Info, $\mathrm{n}^{\circ} 20$ (2011), pp. 21-36.

CALLANAN, Valerie; ROSENBERGER, Jared S., "Media, Gender, and Fear of Crime", Criminal Justice Review, vol. 40, $\mathrm{n}^{\circ} 3$ (2015), pp. 322-339.

CENTRO UC ENCUESTAS Y ESTUDIOS LONGITUDINALES, Percepción del Servicio de la Defensoría Penal Pública. Santiago, Chile: Facultad de Ciencias Sociales, Pontificia Universidad Católica de Chile, 2016.

COLÉMONT, Ariane; VAN HIEL, Alain; CORNELIS, Ilse, "Five-Factor Model personality dimensions and right-wing attitudes: Psychological bases of punitive attitudes?", Personality and Individual Differences, vol. 50, no 4 (2011), pp. 486-491.

COVINGTON Jeanette; TAYLOR, Ralph B., "Fear of Crime in Urban Residential Neighborhoods: Implications of Between- and Within-Neighborhood Sources for Current Models", The Sociological Quarterly, vol. 32, n 2 (1991), pp. 231-249.

DAMMERT, Lucía; MALONE, Mary Fran T., "Fear of Crime or Fear of Life? Public Insecurities in Chile", Bulletin of Latin American Research, vol. 22, n ${ }^{\circ} 1$ (2003), pp. 79-101.

DAMMERT, Lucía; MALONE, Mary Fran T., "Does It Take a Village? Policing Strategies and Fear of Crime in Latin America", Latin American Politics and Society, vol. 48, $\mathrm{n}^{\circ} 4$ (2006), pp. 27-51. 
DE DONDER, Liesbeth; VERTÉ, Dominique; MESSELLIS, Els, "Fear of crime and elderly people: Key factors that determine fear of crime among elderly people in West Flanders", Aging International, vol. 30, n 4 (2005), pp. 363-376.

DIEZ RIPOLLÉS, José Luis, "El nuevo modelo penal de la seguridad ciudadana", Revista Electrónica de Ciencia Penal y Criminología, n 3 (2004), A6, pp. 1-34.

DIEZ RIPOLLÉS, José Luis, "De la sociedad del riesgo a la seguridad ciudadana: un debate desenfocado", Revista Electrónica de Ciencia Penal y Criminología, $\mathrm{n}^{\circ} 1$ (2005), A7, pp. 1-37.

DOWLER, Kenneth, "Media Consumption and Public Attitudes toward Crime and Justice: The Relationship between Fear of Crime, Punitive Attitudes, and Perceived Police Effectiveness", Journal of Criminal Justice and Popular Culture, vol. 10, $\mathrm{n}^{\circ} 2$ (2003), pp. 109-126.

DUCKITT, John; SIBLEY, Chris G., "Right wing authoritarianism, social dominance orientation and the dimensions of generalized prejudice", European Journal of Personality, vol. 21, $\mathrm{n}^{\circ} 2$ (2007), pp. 113-130.

DUCKITT, John, "Punishment attitudes: their social and psychological basis". En: OSWALD, Margit E.; BIENECK; Steffen; HUPFELD-HEINEMANN, Jorg, Social Psychology of Punishment of Crime. Oxford, UK: Wiley-Blackwell, 2009, pp. 75-92.

DUCKITT, John; BISUMIC, Boris; KRAUSS, Stephen, "A tripartite approach to Right Wing Autoritarianism”, Political Psychology, vol. 31, no 5 (2010), pp. 685-715.

ETCHEBERRY, Alfredo, Derecho Penal: Parte general, Santiago: Editorial Jurídica de Chile, 1998.

FEELEY, Malcom, The process is the punishment: handling cases in a lower criminal court, Russell Sage Foundation, 1992.

FERRARO, Kenneth F.; LAGRANGE, Randy, "The Measurement of Fear of Crime", Sociological Inquiry, vol. 57, $\mathrm{n}^{\circ} 1$ (1987), pp. 70-97.

FERRARO, Kenneth F., "Women's fear of victimization: Shadow of sexual assault?", Social Forces, vol. 75, n 2 (1996), pp. 667-690.

FRANKLIN, Cortney A.; FRANKLIN, Travis W., "Predicting fear of crime: Considering differences across gender", Feminist Criminology, vol. 4, n 1 (2009), pp. 83-106.

FRANKLIN, Travis W.; FRANKLIN, Cortney A.; FEARN, Noelle E., "A Multilevel Analysis of the Vulnerability, Disorder, and Social Integration Models of Fear of Crime", Social Justice Research, vol. 21, n 2 (2008), pp. 204-227.

FUENTEALBA, Pablo; BARRIGA, Omar, "Primera aproximación a la construcción de una Escala de Adhesión a los principios del Derecho Penal (EAPDP). Estudio Piloto en el Conurbano del Gran Concepción, Chile”, Revista Internacional de Sociología, vol. 75, no 2 (2017).

FUENTEALBA, Pablo; LARRAÍN, Beatriz; BARRIGA, Omar, “¿Adhiere la ciudadanía a los principios del derecho penal y procesal penal? El caso del Gran Concepción, Chile", Política Criminal, vol. 13, nº 25 (2018), pp. 233-263.

FUENTES, Juan, "Los medios de comunicación y el Derecho Penal", Revista Electrónica de Ciencia Penal y Criminología, $\mathrm{n}^{\circ} 16$ (2005), A7, pp. 1-51.

GARLAND, David, La cultura del control, Trad. SOZZO, Máximo, España: Ediciones Gedisa, 2005. 
GAROFALO, James, “The Fear of Crime: Causes and Consequences”, Journal of Criminal Law and Criminology, vol. 72, $\mathrm{n}^{\circ} 2$ (1981), pp. 839-857.

GERBER, Mónica; JACKSON, Jonathan, "Justifying violence: legitimacy, ideology and public support for police use of force", Psychology, Crime and Law, vol. 23, $\mathrm{n}^{\mathrm{o}} 1$ (2017) pp. 79-95.

GIBSON, Chris L.; ZHAO, Jihong; LOVRICH, Nicholas P.; GAFFNEY, Michael J., "Social Integration, Individual Perceptions of Collective Efficacy, and Fear of Crime in Three Cities", Justice Quarterly, vol. 19, n 3 (2002), pp. 537-564.

GRINA, Jana; BERG, Robin; AKRAMI, Nazar; SIDANIUS, Jim, "Political Orientation and Dominance: Are people on the political right more dominant?", Personality and individual differences, vol. 1, no 94 (2016), pp. 113-117.

HALE, Chris, "Fear of crime: A review of the literature", International Review of Victimology, vol. 4, n 2 (1996), pp. 79-150.

HAMILTON, Claire, "Reconceptualizing penalty: Towards a multidimensional measure of punitivness", British Journal of Criminology, vol. 54, no 2 (2014), pp. 321-343.

HENSON, Billy; REYNS, Bradford W., "The Only Thing We Have to Fear Is Fear Itself... and Crime: The Current State of the Fear of Crime Literature and Where It Should Go Next", Sociology Compass, vol. 9, n² 2 (2015), pp. 91-103.

INTRAVIA, Jonathan; WOLFF, Kevin T.; PAEZ, Rocio; GIBBS, Benjamin R., "Investigating the relationship between social media consumption and fear of crime: A partial analysis of mostly young adults", Computers in Human Behavior, vol. 77 (2017), pp. 158-168.

JAMIESON, Patrick E.; ROMER, Daniel, "Violence in Popular U.S. Prime Time TV Dramas and the Cultivation of Fear: A Time Series Analysis", Media and Communication, vol. 2, $\mathrm{n}^{\circ} 2$ (2014), pp. 31-41.

KOHM, Steven A.; WAID-LINDBERG, Courtney A.; WEINRATH, Michael; O'CONNOR-SHELLEY, Tara; DOBBS, Rhonda R., "The Impact of Media on Fear of Crime among University Students: A Cross-National Comparison", Canadian Journal of Criminology and Criminal Justice, vol. 54, ${ }^{\circ} 1$ (2012), pp. 67-100.

LAGRANGE, Randy; FERRARO, Kenneth F., "Assessing Age and Gender Differences in Perceived Risk and Fear of Crime", Criminology, vol. 27, n 4 (1989), pp. 697-720.

MARKET OPINION RESEARCH INVESTIGATION, Barómetro de la Política Abril 2016, Santiago, Chile: CERC-MORI, 2016.

MATTHEWS, Roger, "The Myth of Punitiveness", Theoretical Criminology, vol. 9, n 2 (2005), pp. 175-201.

MEDINA, Juanjo, "Inseguridad Ciudadana, Miedo al Delito y Policía en España”, Revista Electrónica de Ciencia Penal y Criminología, n 3 (2003), A5, pp. 1-21.

MORGAN, Michael; SHANAHAN, James; SIGNORIELLI, Nancy, "Cultivation Theory in the Twenty-First Century”, en: FORTNER, Robert S.; FACKLER, P. Mark (Eds.), The Handbook of Media and Mass Communication Theory, Hoboken, NJ: John Wiley and Sons, Inc., 2014, pp. 480-497.

PRATTO, Felicia; SIDANIUS, James; STALLWORTH, Lisa; MALLE, Bertram, "Social Dominance Orientation: A personality variable predicting social and political attitudes", Personality and Social Psychology, vol. 67, n 4 (1994), pp. 741-763. 
RADER, Nicole E., "The Threat of Victimization: A Theoretical Reconceptualization of Fear of Crime", Sociological Spectrum: Mid-South Sociological Association, vol. 24, n 6 (2004), pp. 689-704.

RADER, Nicole E.; MAY, David C.; GOODRUM, Sarah, "An Empirical Assessment of the "Threat of Victimization": Considering Fear of Crime, Perceived Risks, Avoidance, and Defensive Behaviours", Sociological Spectrum: Mid-South Sociological Association, vol. 27, ${ }^{\circ} 5$ (2007), pp. 475-505

RADER, Nicole E.; HAYNES, Stacy H., "Gendered fear of crime socialization: An extension of Akers's social learning theory", Feminist Criminology, vol. 6, $\mathrm{n}^{\circ} 4$ (2011), pp. 291-307.

RADER, Nicole E., "Fear of Crime", Oxford Research Encyclopedia of Criminology (2017).

ROBERTS, Julian V.; STALANS, Loretta J.; INDERMAUR, David; HOUGH, Mike, Penal populism and public opinion: five lessons from five countries, New York: Oxford University Press, 2003.

ROBERTS, Julian V.; HOUGH, Mike, Understanding public attitudes to criminal justice, Maidenhead, UK: Open University Press, 2005.

ROBERTS, Julian V.; HOUGH, Mike; JACKSON, Jonathan; GERBER, Monica M., "Public Opinion towards the Lay Magistracy and the Sentencing Council Guideline: the effects of information on attitudes", British Journal of Criminology, vol. 52, $\mathrm{n}^{\circ} 6$ (2012), pp. 1072-1091.

ROUNTREE, Pamela W.; LAND, Kenneth C., "Perceived Risk versus Fear of Crime: Empirical Evidence of Conceptually Distinct Reactions in Survey Data", Social Forces, vol. 74, n 4 (1996), pp. 1353-1376.

RUIZ, Enrique, El Derecho Penal Sustantivo y el Proceso Penal. Garantías constitucionales básicas en la realización de la justicia, Madrid: Colex, 1997.

SIDANIUS, Jim; MITCHELL, Michael; HALLEY, Hilary; NAVARRETE, Carlos, "Support for harsh criminal sanctions and criminal justice beliefs: a social dominance perspective", Social Justice Research, vol. 19, no 4 (2006), pp. 433-450.

SILVA, Jesús-María, Aproximaciones al Derecho Penal Contemporáneo, Barcelona: José María Bosch S.A., 1992.

SOTO, Susana, "La influencia de los medios en la percepción social de la delincuencia", Revista Electrónica de Ciencia Penal y Criminología $\mathrm{n}^{\circ} 9$ (2005), A7, pp. 1-46.

TIRONI, Eugenio; AGÜERO, Felipe, “Sobrevivirá el nuevo paisaje político chileno?” Revista Estudios Públicos, vol. 74, nº 1 (1999), pp. 151-158.

TONRY, Michael. "Symbol, substance and severity in western penal policies", Punishment $\&$ Society, vol. $3 \mathrm{n}^{\mathrm{o}} 4$, pp. (2001) 517-536.

TULLOCH, Marian, "The Meaning of Age Differences in the Fear of Crime. Combining Quantitative and Qualitative Approaches", British Journal of Criminology, vol. 40, $\mathrm{n}^{\circ} 3$ (2000), pp. 451-467.

TYLER, Tom; BOECKMANN, Robert, "Three strikes and you are out, but why? The psychology of public support for punishing rule-breakers", Law and Society Review, vol. $31, \mathrm{n}^{\circ} 2$ (1997), pp. 237-266. 
VARONA, Daniel, "Ciudadanos y actitudes punitivas: un estudio piloto de población universitaria española", Revista Española de Investigación Criminológica, $\mathrm{n}^{\circ} 6$ (2008), A8, pp. 1-38.

VARONA, Daniel, i"Somos los españoles punitivos?: actitudes punitivas y reforma penal en España”, Indret: Revista para el Análisis del Derecho, $\mathrm{n}^{\circ} 1$ (2009), pp. 1-31.

VARONA, Daniel, "Medios de comunicación y punitivismo", Indret: Revista para el Análisis del Derecho, $\mathrm{n}^{\circ} 1$ (2011), pp. 1-34.

ZIEGLER, Raphael; MITCHELL, David B., "Aging and fear of crime: An experimental approach to an apparent paradox", Experimental Aging Research, vol. 29, $\mathrm{n}^{\circ} 2$ (2003), pp. 173-187.

\section{Normas consultadas}

Código Penal. Diario Oficial de la República de Chile, Santiago, Chile, 12 de noviembre de 1874.

Código Procesal Penal. Diario Oficial de la República de Chile, Santiago, Chile, 12 de octubre de 2000.

Constitución Política de la República de Chile. Diario Oficial de la República de Chile, Santiago, Chile, 22 de septiembre de 2005.

Convención Americana sobre Derechos Humanos (Pacto de San José de Costa Rica), Conferencia Especializada Interamericana sobre Derechos Humanos (B-32), 7 al 22 de noviembre de 1969, en: https://www.oas.org/es/cidh/docs/enlaces/conferencia\%20interamericana.pdf [visitado el 10.12.2015].

Pacto Internacional de Derechos Civiles y Políticos, Resolución 2200 A (XXI) de la Asamblea General de las Naciones Unidas, 23 de marzo de 1966, en: http://www.un.org/es/comun/docs/?symbol=A/RES/2200(XXI)\&Lang=S\&Area=RE SOLUTION [visitado el 10.12.2015]. 